NBER WORKING PAPER SERIES

REVISITING THE CLASSICAL VIEW OF BENEFIT-BASED TAXATION

Matthew Weinzierl

Working Paper 20735

http://www.nber.org/papers/w20735

\author{
NATIONAL BUREAU OF ECONOMIC RESEARCH \\ 1050 Massachusetts Avenue \\ Cambridge, MA 02138 \\ December 2014
}

Thanks to Alan Auerbach, Rafael Di Tella, Roger Gordon, Louis Kaplow, Wojciech Kopczuk, Ilyana Kuziemko, Benjamin B. Lockwood, Greg Mankiw, David Moss, Kristi Olson, Andreas Peichl, Florian Scheuer, Daniel Shaviro, Pierre Yared, Glen Weyl, and participants at the 2013 NTA conference, NYU Law School Tax Policy Colloquium, Columbia University, and the University of Chicago's Becker Friedman Instituteís inaugural Normative Ethics and Welfare Economics conference. The views expressed herein are those of the author and do not necessarily reflect the views of the National Bureau of Economic Research.

NBER working papers are circulated for discussion and comment purposes. They have not been peer-reviewed or been subject to the review by the NBER Board of Directors that accompanies official NBER publications.

(C) 2014 by Matthew Weinzierl. All rights reserved. Short sections of text, not to exceed two paragraphs, may be quoted without explicit permission provided that full credit, including () notice, is given to the source. 
Revisiting the Classical View of Benefit-Based Taxation

Matthew Weinzierl

NBER Working Paper No. 20735

December 2014, Revised March 2016

JEL No. D63,H21,H41

\begin{abstract}
$\underline{\text { ABSTRACT }}$
This paper explores how the persistently popular "classical" logic of benefit-based taxation, in which an individual's benefit from public goods is tied to his or her income-earning ability, can be incorporated into modern optimal tax theory. If Lindahl's methods are applied to that view of benefits, first-best optimal policy can be characterized analytically as depending on a few potentially estimable statistics, in particular the coefficient of complementarity between public goods and innate talent. Constrained optimal policy with a Pareto-efficient objective that strikes a balance-controlled by a single parameter-between this principle and the familiar utilitarian criterion can be simulated using conventional constraints and methods. A wide range of optimal policy outcomes can result, including those that match well several features of existing policies. To the extent that such an objective reflects the mixed normative reasoning behind prevailing policies, this model may offer a useful approach to a positive optimal tax theory.
\end{abstract}

\author{
Matthew Weinzierl \\ Harvard Business School \\ 277 Morgan \\ Soldiers Field \\ Boston, MA 02163 \\ and NBER \\ mweinzierl@hbs.edu
}




\title{
Revisiting the Classical View of Benefit-Based Taxation
}

\author{
Matthew Weinzierl*
}

January 29, 2016

\begin{abstract}
This paper explores how the persistently popular "classical" logic of benefit based taxation, in which an individual's benefit from public goods is tied to his or her income-earning ability, can be incorporated into modern optimal tax theory. If Lindahl's methods are applied to that view of benefits, first-best optimal policy can be characterized analytically as depending on a few potentially estimable statistics, in particular the coefficient of complementarity between public goods and endowed ability. Constrained optimal policy with a Pareto-efficient objective that strikes a balance-controlled by a single parameter-between this principle and the familiar utilitarian criterion can be simulated using conventional constraints and methods. A wide range of optimal policy outcomes can result, including those that match well several features of existing policies. To the extent that such an objective reflects the mixed normative reasoning behind prevailing policies, this model may offer a useful approach to a positive optimal tax theory.
\end{abstract}

\section{Introduction}

"These [urban] centers and their wealthy residents have cause for satisfaction and thanksgiving that their incomes are so bountiful and that the country has provided them with such great opportunities, rather than occasion for criticising the requirement of a moderate contribution to the nation which has rendered such incomes possible."

Roy Blakey, American Economic Review, 1913

In February, 1913, the Sixteenth Amendment to the U.S. Constitution was passed, allowing for the direct taxation of incomes. One month later, the nascent American Economic Review included a paper by Roy Blakey (1913), a noted tax expert and University of Minnesota professor, that gave the preceding argument for the propriety of taxing large (mainly urban) incomes.

In 1935, U.S. President Franklin Delano Roosevelt sought to substantially increase the progressivity of taxes. He argued as follows.

"With the enactment of the Income Tax Law of 1913, the Federal Government began to apply effectively the widely accepted principle that taxes should be levied in proportion to ability to pay and in proportion to the benefits received. Income was

${ }^{*}$ Harvard Business School and NBER, mweinzierl@hbs.edu. Thanks to the editor, Frederic Vermeulen, the referees, and Alan Auerbach, Rafael Di Tella, Roger Gordon, Louis Kaplow, Wojciech Kopczuk, Ilyana Kuziemko, Benjamin B. Lockwood, Greg Mankiw, David Moss, Kristi Olson, Andreas Peichl, Florian Scheuer, Daniel Shaviro, Pierre Yared, Glen Weyl, and participants at the 2013 NTA conference, NYU Law School Tax Policy Colloquium, Columbia University, and the University of Chicago's Becker Friedman Institute's inaugural Normative Ethics and Welfare Economics conference. 
wisely chosen as the measure of benefits and of ability to pay. This was, and still is, a wholesome guide for national policy. It should be retained as the governing principle of Federal taxation...."

In 2011, U.S. President Barack Obama also sought to increase top marginal income tax rates. He applied this reasoning:

"As a country that values fairness, wealthier individuals have traditionally borne a greater share of this [tax] burden than the middle class or those less fortunate. Everybody pays, but the wealthier have borne a little more. This is not because we begrudge those who've done well — we rightly celebrate their success. Instead, it's a basic reflection of our belief that those who've benefited most from our way of life can afford to give back a little bit more."

Modern tax theorists will find the normative arguments underlying these quotations both familiar and strange. All three refer to the logic of "benefit-based taxation," under which people ought to pay taxes that depend on how much they benefit from public goods. All three quotes also refer to the logic of "ability-based taxation," under which people ought to pay taxes that depend on how much they are hurt by having to earn the money to pay. Introductory public finance textbooks describe these two ideas as the classic principles of optimal tax design. But they are usually considered alternatives, not complements. To modern tax theorists working in the tradition of James Mirrlees (1971), stranger still is the use of these principles at all, as modern tax theory has largely moved away from them in favor of an approach emphasizing social welfare maximization.

Two hundred years ago, however, the normative principle underlying these statements would have been recognized immediately as Adam Smith's (1776) first maxim of taxation:

"The subjects of every state ought to contribute toward the support of the government, as near as possible, in proportion to their respective abilities; that is in proportion to the revenue which they respectively enjoy under the protection of the state."

Like those quoted above, Smith argues that one's income-as a measure of one's ability to pay-is a measure of one's benefit from the state. Because he supports benefit-based taxation more generally, Smith believes ability to pay is therefore an appropriate basis for taxation. ${ }^{1}$ Simply put, Smith endorses benefit-as-ability-based taxation. Richard Musgrave (1959) labeled this logic the "classical" view of benefit-based taxation, a label I adopt in this paper.

This classical view of benefit-based taxation was highly influential in the late 18th and early 19th centuries but waned as John Stuart Mill's (1871) purely ability-based reasoning gained favor and the canonical contributions of Erik Lindahl (1919) shifted the focus of benefit-based tax research. ${ }^{2}$ The idea of benefit-as-ability was not further explored, while benefit-based and ability-based reasoning were developed as separate ideas. Benefit-based reasoning was assigned a subsidiary role in tax theory, namely as a means by which to value and assign the costs of public expenditures while, crucially, taking the distribution of income as given. ${ }^{3}$ (Note that the classic view has endogeneity of

\footnotetext{
${ }^{1}$ Smith argued that the preferred way of paying for public goods was to have them privately or locally managed, with user fees mechanically tying the funding for these institutions to individual benefits, though he recognized user fees were infeasible in many cases. See Smith (1776, Book V Article 1)

${ }^{2}$ As the remarkable surveys by Edwin Seligman (1908) and Richard Musgrave (1959) make clear, benefit based reasoning was a prominent, at times leading, approach among tax theorists through the 19th century. William Petty (1677) anticipated Smith's view, and Hobbes, Hume, and Rousseau among others subscribed to it in some form.

${ }^{3}$ Lindahl himself viewed his theory as conditional in this way, a view criticized as untenable by Samuelson (1955).
} 
the income distribution as its core component). Ability-based reasoning was absorbed into the nowdominant Mirrleesian approach, as Mirrlees (1971) made differences in the ability to earn income the linchpin of taxation in his theory. ${ }^{4}$ The classical benefit-based logic exerted little influence on the welfarist objective assumed in modern Mirrleesian theory.

In normative terms, the shift from the classical benefit-based view to the dominant modern approach, which pursues so-called "endowment taxation," is quite substantial. Under the modern approach, an individual's income-earning ability is taken as a given, and as ability makes it easier to obtain consumption in exchange for leisure, social welfare maximization will tend to imply taxing those with higher endowments to supplement the resources of others. In contrast, the classical benefit-based view treats an individual's ability as a function of the activities of the state to which that individual contributes. Any endowments are moot unless individuals cooperate to fund public goods that set the stage for abilities to develop. Under this approach, taxation is merely the means by which individuals pay for these public goods cooperatively, each according to how much he or she values them.

Perhaps due in part to this normative contrast, the modern shift away from using the benefitbased approach, in any form, as a general principle of taxation appears nearly complete. The authoritative review of modern tax theory entitled the Mirrlees Review (IFS, 2010) makes no reference to Lindahl's (1919) canonical development of a benefit-based theory or to any of the relatively few more recent refinements of it. Anthony Atkinson and Joseph Stiglitz's (1980) classic text and Louis Kaplow's (2008) invaluable modern treatise each devote only a few pages among hundreds to benefit-based taxation, the latter largely to point out its weaknesses (as discussed below). Neither Bernard Salanié (2011), in his essential textbook on the economics of taxation, nor Robin Boadway (2012), in his excellent survey of optimal tax theory's implications for policy, mention Lindahl or benefit-based taxes. ${ }^{5}$

The long-standing role for classical benefit-based logic in public reasoning over taxes stands in stark contrast to this momentum away from it in modern theory. The purpose of this paper is to explore whether we might reconcile this disconnect by incorporating the classical view of benefitbased taxation into the modern framework of optimal tax theory, thereby resuscitating it as part of how we understand policy design.

The first contribution of this paper is the finding that the classical benefit-based view can fit neatly into the Mirrleesian approach once one makes a simple-and arguably needed-change to the standard setup: that is, allowing individual income-earning ability to be a function of both endowed ability and public goods. Once public goods matter for ability, the classical benefit-as-ability view links seamlessly with the modern model. Thus, both first-best and constrained optimal benefitbased policy can be analyzed within the formal structure of modern tax theory and characterized using familiar methods. ${ }^{6}$ Of course, the normative contrast between the classical benefit-based view and endowment taxation remains.

In particular, first-best policy according to this view of benefit-based taxation can be characterized in terms of simple and potentially observable elasticity parameters if we apply Lindahl's well-known method of measuring benefit. In this paper, we derive the version of the Samuelson

\footnotetext{
${ }^{4}$ The Mirrleesian approach's linkage of ability to pay and ability to earn relies on its assumption-Mirrlees (1971) makes it his second assumption-that tastes are homogenous. See Lockwood and Weinzierl (2015a).

${ }^{5}$ As noted, benefit-based reasoning continues to occupy a prominent but narrow role in studies of public goods provision that take the income distribution as given. See, for example, Aaron and McGuire (1970) and the large literature following upon their work, as cited below.

${ }^{6}$ One way to interpret this contribution is that it shows how this classical view might-by linking benefit to abilityavoid the common critique of benefit-based reasoning that it "has little more than emotive content" and "leads nowhere at all," as Henry Simons (1938) put it (quoted in Daniel Shaviro 2013).
} 
rule for the optimal extent of public goods under the classical benefit-based view. We also obtain a straightforward condition determining the progressivity of optimal average tax rates, which turns out to depend in an intuitive way on the size of the Hicksian coefficient of complementarity between public goods and endowed ability. These conditions reduce to especially simple relationships if we assume that the ability production function takes certain forms. As an interesting aside, assuming those same forms and a familiar form for the individual utility function we find that optimal benefit-as-ability-based taxation quantitatively resembles Mill's preferred "equal sacrifice" taxation, a possibility hinted at informally nearly forty years ago by Martin Feldstein (1976).

As with the first-best policy, we find that the classical view's linkage of benefit and ability facilitates the analysis of constrained optimal benefit-based policy. We need to modify only the objective, not the constraints, of conventional Mirrleesian analysis to characterize how different assumptions about the interaction of public goods and endowed ability affect the progressivity of constrained optimal benefit-based policy. To address the limitation that the classical benefit-based view does not provide a ranking of allocations other than the first-best, we modify the standard conventional utilitarian objective function to allow the planner to choose the allocation, from the set of incentive compatible allocations, that deviates least from the first-best benefit-based allocation while respecting Pareto efficiency.

Why go to the trouble of attempting such a resuscitation?

The statements provided at the start of this paper suggest that the classical view of benefitbased taxation is included in the criteria used to judge, or at least justify, tax policy in the United States. If one takes a positive approach to specifying the objective of optimal taxation, that view therefore ought to be included in our models, as well. ${ }^{7}$ While conventional optimal tax analysis uses an objective for policy based on philosophical reasoning, recent work has pursued the idea of basing that objective on evidence of the normative priorities that prevail in society. ${ }^{8}$ An important feature of this "positive optimal tax theory" is its inclusion of multiple normative criteria, as a wide range of evidence has shown that most persons base their moral judgments on more than one principle. $^{9}$

The second contribution of this paper is, therefore, to explore whether an optimal tax model with a mixed objective function that gives weight to both the classical view of benefit-based taxation and the conventional utilitarian criterion has quantitative explanatory power. To implement that analysis, I take advantage of a convenient feature of the objective function used in the preceding first-best analysis. That objective function differs from the conventional utilitarian criterion for optimal policy in only one way: it treats gains and losses of utility from a benchmark allocation asymmetrically, such that the utilitarian criterion is equivalent to restoring symmetry to that

\footnotetext{
${ }^{7}$ Some readers may question the usefulness of popular conceptions of economic justice for normative policy analysis. The perspective implicit in this paper is that a back-and-forth between introspective reasoning on moral principles and robust popular reasoning is likely to be productive. See Steven M. Sheffrin (2013) for the development of the related idea of a role for "folk justice" and Gaertner and Schokkaert (2012) for related arguments behind the use of "empirical social choice" methods.

${ }^{8}$ See Weinzierl (2014) and Saez and Stantcheva (2014); also see Zelenak (2006) for a different, legal theory, perspective and Lockwood and Weinzierl (2015) for related evidence. Such a positive optimal tax theory differs from a purely positive theory of taxation, where the political process and self-interest of voters play central roles. Positive optimal tax theory retains the conventional theory's focus on an objective that reflects the moral reasoning of an impartial observer.

${ }^{9}$ See the discussion of normative diversity in Weinzierl (2014). Not mentioned there, however, is that Adam Smith appears to have had a similarly mixed perspective. While in his first maxim he seems to argue for proportional taxation, he writes at another point in the same book: "The necessaries of life occasion the great expence of the poor. They find it difficult to get food, and the greater part of their little revenue is spent in getting it. The luxuries and vanities of life occasion the principal expence of the rich...It is not very unreasonable that the rich should contribute to the public expence, not only in proportion to their revenue, but something more than in that proportion."
} 
objective function. Moreover, that asymmetry is controlled by a single parameter that I label $\delta$ and which provides a simple way to adjust the relative weights given to the classical benefit-based criterion and the conventional utilitarian criterion. By varying $\delta$, we find that a wide range of optimal policy outcomes can result, including those consistent with existing policy. These results suggest that this model may offer a useful approach to a positive optimal tax theory.

Readers familiar with Weinzierl (2014) will find these two papers' analyses complementary. In that paper, I demonstrate public affinity for a different (but as noted below, related) principle of tax design: equal sacrifice. I then show that a role for equal sacrifice in the optimal tax objective function yields policy implications that resolve a number of puzzling gaps between conventional theory and robust features of prevailing tax policy. I leverage a similar, though streamlined, technique in section 3 of this paper to explore the policy implications of classical benefit-based taxation, which not surprisingly resemble those of equal sacrifice in important ways. Together, these two papers formalize and characterize the implications of including in the policy objective two long-standing and popular normative approaches to taxation that depart from the conventional approach in optimal tax theory. In so doing, these papers can help us understand why actual tax policy looks the way it does.

Before proceeding, it may be important to highlight a few potentially related things that this paper is not trying to do.

First, this paper is not intended to defend classical benefit-based taxation as a normative principle. Other principles, including utilitarianism, may well be preferable from the perspective of moral and political philosophy. Instead, this paper is intended to capture the view of benefit-based taxation that arose in early sophisticated thinking about optimal taxation and that appears to have retained a prominent role in public reasoning over taxes despite the strong criticisms of more recent tax theorists.

Second, this paper does not claim to resolve the debate over whether the right approach to linking taxes to benefit is Lindahl's. The proper way to turn the normative intuition behind benefitbased taxation into individual tax burdens has long been a topic of study (prominent examples include Aaron and McGuire 1970, 1976; Brennan 1976, 1979; West and Staaf 1979, Moulin 1987, and Hines 2000). ${ }^{10}$ Instead, I view Lindahl's approach as a natural way to formalize the informal notion-implicit in rhetorical appeals to benefit-based taxation-that people ought to "pay for what they get" from public goods just as they do in the market for private goods. The most well-known example of this metaphor is usually attributed to U.S. Supreme Court Justice Oliver Wendell Holmes, who served on the Court from 1902 through 1932: "I like to pay taxes. With them I buy civilization." ${ }^{11}$ In fact, Lindahl entitled the full statement of his approach "Just Taxation A Positive Solution," and described it as a model of how "the distribution of the total cost of the collective goods...is to be solved by free agreement...as a kind of economic exchange."

\footnotetext{
${ }^{10}$ One of many disagreements from that debate is over the justifiability of using of an individual's marginal willingness to pay for public goods to measure that individual's benefit. The Lindahl answer to that question, as stated by Aaron and McGuire (1970), criticized by Brennan (1976), and discussed by West and Straaf (1979), is to have two sets of taxes, one of which may offset differences in inframarginal benefits (as well as other undesirable inequalities) and the second of which implements the Lindahl benefit-based equilibrium. I adopt a version of that approach by having the objective of the social planner give weight to both the distribution of welfare (in the conventional utilitarian sense) and to the allocation's proximity to the first-best benefit-based allocation. Note that this paper thereby aligns with the arguments of Samuelson (1954, foonote 9). An alternative approach would be to tie taxes to the total, inframarginal benefits from public goods, perhaps along the lines of Moulin (1987).

${ }^{11}$ Holmes wrote a similar phrase into his decision on a 1927 case before the Court. It is worth recalling that, at the time, the U.S. income tax was highly concentrated on only the wealthiest Americans, so Holmes was effectively arguing on behalf of progressive taxation. The wide use of his dictum in popular writings on taxation over the intervening decades suggests that it has broad appeal.
} 
Third, the mixed normative objective utilized in this paper is not meant as an alternative to the most general forms of modern optimal tax theory. As has been made clear in work by Stiglitz (1987) and Iván Werning (2007), among others, Mirrleesian optimal tax theory imposes only the requirement of Pareto efficiency on the set of feasible and incentive compatible allocations. The objectives I consider satisfy Pareto efficiency as well, so in principle they could be modeled in alternative ways that are closer-in formal terms-to the standard approach (i.e., following the technique of Emmanuel Saez and Stefanie Stantcheva, 2015). This paper's approach chooses among Pareto-efficient allocations by assigning weights to a small number of normative principles with apparent empirical relevance.

The paper proceeds as follows. Section 1 formalizes the classical benefit-based view and analytically characterizes optimal policy under it by applying Lindahl's methodology to an (otherwise standard) optimal tax model in which ability depends on public goods as well as endowed ability. Section 2 quantitatively characterizes constrained-optimal (second-best) policy, again using the conventional modern optimal tax model modified only in its objective, which in this case is to deviate as little as possible from the allocation preferred by the classical benefit-based view. Section 3 extends that constrained-optimal analysis to the case of an objective function that can be interpreted as giving weight to both utilitarianism and the classical benefit-based view. Section 4 concludes. The Appendix contains additional examples of public rhetoric drawing on the classical benefit-based view as well as the proofs of analytical results.

\section{Analytical characterization of classical benefit-based taxation}

In this section I show how a single modification of the standard Mirrleesian optimal tax model enables us to formalize classical benefit-based taxation (hereafter, CBBT) and characterize optimal policy in terms of simple, potentially observable statistics.

\subsection{The model}

A population of individuals differ in their abilities to earn income. In conventional models, these abilities are interpreted as innate and fixed relative to public goods. ${ }^{12}$ The innovation in this paper is that individuals' income-earning abilities are functions of both endowed ability and public goods funded by tax revenue. ${ }^{13}$ As mutually exclusive categories, endowed ability and public goods can be thought of as, respectively, the genetic or other endowments not affected by the size and scope of the state and the broad set of activities with which the state supports the functioning of an economy. Note that this paper takes only the first, most basic, step toward modeling the effect of these public goods on individuals' abilities by leaving unexplored their composition. Future research may show how the mix, design, and implementation of public goods matter, as well. ${ }^{14}$

\footnotetext{
${ }^{12}$ Much recent work in the Mirrleesian literature has considered other sources of endogeneity, such as human capital investment. See Kapicka (2006), Gelber and Weinzierl (2015), Best and Kleven (2013), Stantcheva (2014), among others.

${ }^{13}$ An innovative paper by Matsumoto (2001) is the only other analysis of which I am aware in which public goods augment individual abilities in an optimal tax model. His focus is on how public goods can thereby relax incentive constraints.

${ }^{14}$ Much of public spending in advanced economies is for social insurance rather than "productive" public goods, a distinction this paper's model can accommodate in a number of ways. First, in the static setting of this paper, the value of social insurance to welfare may be captured by the policymaker's weight on the utilitarian objective discussed in section 3, while the ability production function $f(a, G)$ may be specified to reflect the effect of public goods on ability including all forms of government spending (i.e., $G$ may have weaker marginal effects if it is made up largely of social insurance). Alternatively, in a dynamic model with shocks that may be insured against (perhaps through
} 
Formally, income-earning ability $w_{i}=f\left(a_{i}, G\right)$, where $i \in I$ indexes endowed ability types $a_{i}$, $G \geq 0$ is the level of spending on public goods, and $f(\cdot): \mathbb{R}^{+} \times \mathbb{R}^{+} \rightarrow \mathbb{R}^{+}$is a differentiable ability production function. The conventional model is a special case in which $f\left(a_{i}, G\right)=a_{i}$ for all $i \in I$ and any $G$.

An individual of type $i$ derives utility according to

$$
U\left(c_{i}, l_{i}\right)=u\left(c_{i}, \frac{y_{i}}{f\left(a_{i}, G\right)}\right),
$$

where $c_{i}$ is private consumption for individual $i$ and $y_{i}$ is $i$ 's income, so that $\frac{y_{i}}{w_{i}}$ is work effort. Denote partial derivatives of this utility function with respect to consumption and effort with $u_{c}\left(c_{i}, \frac{y_{i}}{f\left(a_{i}, G\right)}\right)$ and $u_{l}\left(c_{i}, \frac{y_{i}}{f\left(a_{i}, G\right)}\right)$. Note that this utility function does not assume additive separability between the utility from consumption and the disutility from effort, a simplifying assumption often made in optimal tax models.

A social planner chooses a tax system, including an optimal $G^{*}$. Individuals take that system as given and maximize their own utility, yielding equilibrium consumption and income allocations $\left\{c_{i}^{*}, y_{i}^{*}\right\}_{i=1}^{I}$ and utility levels

$$
U_{i}^{*}=u\left(c_{i}^{*}, \frac{y_{i}^{*}}{f\left(a_{i}, G^{*}\right)}\right)
$$

for all $i \in I$. Note that there may be multiple optimal policy equilibria, as discussed below.

At this point, it may be worth noting that the simple change of making income-earning ability depend on public goods raises a number of questions for conventional Mirrleesian optimal taxation that could be pursued in future research.

\section{$1.2 \quad$ First-best classical benefit-based taxes}

With the endogenous ability defined above, we can now apply Lindahl's theory to determine optimal benefit-based taxes. The core insight of Lindahl's work starts with the idea of personalized tax "prices," or shares. ${ }^{15}$ The planner specifies this set of shares $\left\{\tau_{i}\right\}$, and individual $i$ therefore faces the budget constraint

$$
y_{i}-c_{i}-\tau_{i} p G \geq 0,
$$

where $p$ is the per-unit cost of public goods relative to private consumption goods and $\tau_{i}$ is the share of the total cost of public goods paid for by the individuals of type $i^{16}$

Lindahl's approach as stated here is a "first-best" one, as it assumes that individual type is observable; i.e., the tax planner can assign personalized shares $\tau_{i}$ to individuals. This unrealistic assumption has long been a target for criticism of benefit-based taxation in the Lindahl tradition. In the next section, I show how the classical logic for benefit-based taxes-due to its treatment of ability as benefit-allows us to accommodate incentive compatibility within the Lindahl approach just as the Mirrlees model does.

government activities), social insurance spending may fit into a benefit-based framework more directly, though not through its effects on ability, so that the model would distinguish between the types of $G$ and how they generate benefit.

${ }^{15} \mathrm{I}$ assume the public goods are entirely nonexcludable. Taxing the benefits from excludable public goods raises additional possibilities: see for example Hellwig (2005).

${ }^{16}$ I am restricting attention to what Kaneko (1977a, 1977b) calls the "ratio equilibria," a subset of the full class of Lindahl equilibria. Ratio equilibria are those in which each individual's tax payment is equal to a personalized scalar (here denoted $\tau_{i}$ for individual $i$ ) multiplied by the total cost of public goods, such that all individuals maximize utility and agree on the optimal level of public goods. I thank a referee for prompting this note. 
In this section, I will follow Lindahl and focus on first-best benefit-based policies. This is not merely for analytical tractability, though that is a side benefit. Rather, first-best policies are the most direct guide to a normative principle's effects on policy, as evidenced by the analytical results below and how they compare to first-best policies under a conventional utilitarian criterion (which is fully egalitarian). More concretely, first-best policies are essential ingredients in the calculation of constrained (second-best) optimal policies in the positive optimal tax model that I will analyze numerically in the next section.

Lindahl's approach then has us consider a hypothetical scenario in which each individual $i$ is allowed to choose her own consumption, work effort, and, importantly, level of public goods provision that maximize her utility subject to her personal budget constraint, taking the tax share $\tau_{i}$ as given. Denote this individually-optimal level $G_{i}$ and let $\lambda$ denote the multiplier on the budget constraint (3). The individual first order conditions are as follows:

$$
\begin{aligned}
u_{c}\left(c_{i}, \frac{y_{i}}{f\left(a_{i}, G\right)}\right) & =\lambda, \\
\frac{1}{f\left(a_{i}, G_{i}\right)} u_{l}\left(c_{i}, \frac{y_{i}}{f\left(a_{i}, G\right)}\right) & =-\lambda, \\
\frac{-y_{i} f_{G}\left(a_{i}, G_{i}\right)}{f\left(a_{i}, G_{i}\right)} \frac{1}{f\left(a_{i}, G_{i}\right)} u_{l}\left(c_{i}, \frac{y_{i}}{f\left(a_{i}, G\right)}\right) & =\tau_{i} p \lambda .
\end{aligned}
$$

Lindahl defined optimal policy as that in which two conditions are satisfied: first, the personalized shares cause each type to prefer the same quantity of public goods; second, the cost of the public goods is fully covered by tax payments. These requirements can be stated formally.

Definition 1 A First-Best Lindahl Equilibrium: The policy $\left\{\left\{\tau_{i}^{F B}\right\}_{i}, G^{F B}\right\}$ is a First-Best Lindahl Equilibrium if and only if individuals maximize utility and the following conditions hold:

$$
\begin{gathered}
G_{i}=G^{F B} \forall i, \\
\sum_{i \in I} \tau_{i}^{F B}=1 .
\end{gathered}
$$

Note that this definition describes 'a' First Best Lindahl Equilibrium, so uniqueness is not implied. With a general form for the ability production function, multiple policies $\left\{\left\{\tau_{i}^{F B}\right\}_{i}, G^{F B}\right\}$ may satisfy the conditions of Definition 1, and the analytical results below apply to any FirstBest Lindahl Equilibrium. For example, if public goods spending initially benefits all individuals proportionally but, at higher levels, benefits high-ability individuals more than proportionally, there may exist an optimum with small $G$ and flat tax shares and another optimum with large $G$ and progressive tax shares. Further study of this possibility, including empirical work, is an important next step in the theory and application of CBBT.

Next, I turn to characterizing optimal policy with conditions on its components, $G^{F B}$ and $\left\{\tau_{i}^{F B}\right\}_{i}$ that depend on only (at least potentially) estimable statistics. All proofs of the following results are collected in the printed appendix at the end of this paper.

\subsubsection{First-best level of public goods spending (Samuelson rule)}

First, we can derive the version of the Samuelson rule (1955) that determines the optimal level of public spending in this model. This version turns out to depend on an elasticity that may be a fruitful target for empirical research, defined as follows: 
Definition 2 Define the elasticity of individual i's income-earning ability with respect to public goods, $\varepsilon_{i}^{G}(G)$, as:

$$
\varepsilon_{i}^{G}(G)=\frac{f_{G}\left(a_{i}, G\right)}{f\left(a_{i}, G\right)} G
$$

Using this elasticity, we can state the following result.

Proposition 1 Samuelson Rule: If the policy $\left\{\left\{\tau_{i}^{F B}\right\}_{i}, G^{F B}\right\}$ is a First-Best Lindahl Equilibrium, then the following condition is satisfied:

$$
\sum_{i \in I} \varepsilon_{i}^{G}\left(G^{F B}\right) y_{i}=p G^{F B}
$$

Equivalently, the sum of individuals' marginal rates of substitution of private consumption for public goods is equal to the marginal rate of transformation between them, when individuals choose according to (4), (5), and (6).

This result simplifies further when the ability production function takes the familiar multiplicative or Cobb-Douglas forms. The key to these simplifications is that the elasticity defined above becomes constant across individuals. In particular,

Lemma 1 If the ability production function is multiplicative, such that $f\left(a_{i}, G\right)=h\left(a_{i}\right) g(G)$ for some differentiable functions $h\left(a_{i}\right), g(G)$, both $\mathbb{R}^{+} \rightarrow \mathbb{R}^{+}$, then at a given $G$ the elasticity of individual $i$ 's income-earning ability with respect to public goods, $\varepsilon_{i}^{G}(G)$, satisfies:

$$
\varepsilon_{i}^{G}(G)=\frac{g^{\prime}(G) G}{g(G)}=\varepsilon_{j}^{G}(G) \equiv \varepsilon^{G}(G) \forall i, j .
$$

Furthermore, if $g(G)=G^{\gamma}$ for some $\gamma>0$,

$$
\varepsilon^{G}(G)=\gamma \forall G
$$

With these results, we have the following corollary of Proposition 1.

Corollary 1 If the policy $\left\{\left\{\tau_{i}^{F B}\right\}_{i}, G^{F B}\right\}$ is a First-Best Lindahl Equilibrium, and if the ability production function is multiplicative, such that $f\left(a_{i}, G\right)=h\left(a_{i}\right) g(G)$ for some differentiable functions $h\left(a_{i}\right), g(G)$, both $\mathbb{R}^{+} \rightarrow \mathbb{R}^{+}$, then $G^{F B}$ satisfies:

$$
\varepsilon^{G}\left(G^{F B}\right) \sum_{i \in I} y_{i}=p G^{F B}
$$

Furthermore, if $g(G)=g^{\gamma}$ for some $\gamma>0$, then spending on $G^{F B}$ is a share $\gamma$ of total output:

$$
\gamma \sum_{i \in I} y_{i}=p G^{F B}
$$

In words, Corollary 1 says that in the case of a multiplicative ability production function society ought to devote a fraction of its output equal to the (uniform) elasticity of income-earning ability with respect to public goods, $\varepsilon^{G}\left(G^{F B}\right)$, toward funding the public goods that magnify endowed abilities. If income-earning ability is log-linear in public goods with coefficient $\gamma$-such as the familiar Cobb-Douglas form-that fraction is simply $\gamma$. 
This corollary provides a neat illustration of how taxes in the Lindahl equilibrium enable private market efficiency in the public sector. Suppose that at the efficient outcome the provider of public goods is paid a price for its output equal to the marginal product of public goods. That marginal product is $\sum f_{G}\left(a_{i}, G\right) l_{i}$, where $l_{i}=y_{i} / f\left(a_{i}, G\right)$ is the (held fixed) labor effort for individual $i$. The total payments to public goods would then be $G \sum f_{G}\left(a_{i}, G\right) y_{i} / f\left(a_{i}, G\right)$. Now impose Cobb-Douglas and this becomes $\gamma \sum y_{i}$, so that the total payments to public goods equals the share $\gamma$ of total income, just as for a factor of production in a competitive equilibrium.

\subsubsection{First-best average tax rates}

Next, we turn to characterizing the taxes paid by each individual in the first-best allocation. As with the optimal level of public goods spending, our results can be expressed in terms of a potentially estimable elasticity.

Definition 3 Define the Hicksian partial elasticity of complementarity between public goods and endowed ability, $\theta_{i}^{G, a}$, as:

$$
\theta_{i}^{G, a}=\frac{f_{G, a}\left(a_{i}, G\right) f\left(a_{i}, G\right)}{f_{G}\left(a_{i}, G\right) f_{a}\left(a_{i}, G\right)}
$$

at a given $G$.

The Hicksian partial elasticity of complementarity has received attention in recent optimal tax analyses that include human capital (see Bovenberg and Jacobs 2011, Stantcheva 2014, and the citations therein). In this paper's context, it captures the degree to which public goods and endowed ability magnify each other in determining income-earning ability. If $\theta_{i}^{G, a} \leq 0$, endowed ability and public goods are not complements in the production of income-earning ability. If $\theta_{i}^{G, a} \in(0,1)$ the elasticity of income-earning ability with respect to the level of public goods spending is positive but decreasing in endowed ability; if $\theta_{i}^{G, a}>1$, the elasticity of income-earning ability with respect to the level of public goods spending is increasing in endowed ability. We can then state the following result.

Proposition 2 Assume public goods and endowed ability have positive partial effects on incomeearning ability: i.e., $f_{G}\left(a_{i}, G\right)>0$ and $f_{a}\left(a_{i}, G\right)>0$ for all $i$. If $\left\{\left\{\tau_{i}^{F B}\right\}_{i}, G^{F B}\right\}$ is a First-Best Lindahl Equilibrium, with corresponding incomes $\left\{y_{i}^{F B}\right\}_{i}$ then the optimal average tax rate on individual $i$ increases (decreases) with endowed ability iff the Hicksian partial elasticity of complementarity between public goods and endowed ability is greater than (less than) one. Formally, define the optimal average tax rate for individual $i$ as $A T R_{i}^{F B}=\tau_{i}^{F B} p G^{F B} / y_{i}^{F B}$. Then,

$$
\frac{\partial A T R_{i}^{F B}}{\partial a_{i}}>(<) 0 \Leftrightarrow \theta_{i}^{G, a}\left(G^{F B}\right)>(<) 1
$$

The intuition for Proposition 2 is as follows. Public goods are assumed to magnify all abilities. ${ }^{17}$ If the effect of public goods on ability has a greater elasticity to endowed ability than does ability itself, that means that there is a complementarity between public goods and ability. ${ }^{18}$ Thus, public

\footnotetext{
${ }^{17}$ In principle, this need not be the case, though if we restrict attention to modern developed economies it is difficult to imagine that any individual's income-earning ability is lowered, in an absolute sense, by the existence of the state.

${ }^{18}$ One can define the elasticity of individual $i$ 's income-earning ability with respect to endowed ability as $\varepsilon_{i}^{a}(G)=$ $\frac{f_{a}\left(a_{i}, G\right)}{f\left(a_{i}, G\right)} a_{i}$ and the elasticity of the effect of public goods on individual $i$ 's income-earning ability with respect to endowed ability as: $\varepsilon_{i}^{G, a}(G)=\frac{f_{G, a}\left(a_{i}, G\right)}{f_{G}\left(a_{i}, G\right)} a_{i}$. The Hicksian partial elasticity of complementarity is the ratio of the latter to the former.
} 
goods spending is a source of greater benefit for those with greater endowed ability, and optimal benefit-based taxation adjusts their taxes up accordingly. Again, note that if the ability production function takes a form in which the effect of $G$ varies in a complicated way with $a$, multiple equilibria with different degrees of tax progressivity (as well as levels of $G$ ) could satisfy the conditions for a First-Best Lindahl Equilibrium.

As with Proposition 1, we can simplify this result if we assume a multiplicative form for the ability production function:

Lemma 2 If the ability production function is multiplicative, such that $f\left(a_{i}, G\right)=h\left(a_{i}\right) g(G)$ for some differentiable functions $h\left(a_{i}\right), g(G)$, both $\mathbb{R}^{+} \rightarrow \mathbb{R}^{+}$, then $\theta_{i}^{G, a}=1$.

The intuition for this lemma is that the multiplicative production function means the elasticity of income-earning ability with respect to the level of public goods spending is the same no matter the level of endowed ability. With these results and Lemma 1, we have the following corollary of Proposition 2.

Corollary 2 If $\left\{\left\{\tau_{i}^{F B}\right\}_{i}, G^{F B}\right\}$ is a First-Best Lindahl Equilibrium, and if the ability production function is multiplicative, such that $f\left(a_{i}, G\right)=h\left(a_{i}\right) g(G)$ for some differentiable functions $h\left(a_{i}\right)$, $g(G)$, both $\mathbb{R}^{+} \rightarrow \mathbb{R}^{+}$, then the optimal tax policy is a uniform average tax rate for all $i \in I$ :

$$
A T R_{i}^{F B}=\varepsilon^{G}\left(G^{F B}\right) \forall i .
$$

Furthermore, if $g(G)=g^{\gamma}$ for some $\gamma>0$, then the optimal tax policy is a uniform tax rate of $\gamma$ :

$$
A T R_{i}^{F B}=\gamma \forall i
$$

Of course, this corollary and Corollary 1 are linked, in that total spending on public goods as a share of output equals this flat average tax rate.

\subsection{Relation to sacrifice theories}

John Stuart Mill's (1871) principle of equal sacrifice was the theory of optimal taxation that displaced Smith's CBBT in the intellectual history of optimal tax theory. Under equal sacrifice, tax burdens are to be distributed so that each taxpayer feels the same sacrifice from contributing to public goods.

A relationship between benefit-based taxation and Equal Sacrifice has long been intuited. For example, in an early critique of the Mirrleesian approach Martin Feldstein (1976) wrote: "Nozick (1974) has recently presented an extensive criticism of the use of utilitarian principles to justify the redistribution of income and wealth...In this context, the principle of benefit taxation or of tax schedules that impose equal utility sacrifice have an appeal that is clearly lacking in the utilitarian framework."

Using the model above, and assuming some specific but familiar functional forms, we can show a quantitative connection that is consistent with this intuition.

To link these principles requires defining "sacrifice." To do so, we consider a hypothetical state in which public goods are provided at their optimal level, $G^{F B}$, for no cost. Sacrifice for individual $i$ is then defined as the decrease in utility of moving from an undistorted optimal position in that hypothetical state to the planner's chosen allocation. 
In the hypothetical, free-public-goods state, the individual sets:

$$
u_{c}\left(c_{i}^{H}, \frac{y_{i}^{H}}{f\left(a_{i}, G^{F B}\right)}\right)=\frac{-1}{f\left(a_{i}, G^{F B}\right)} u_{l}\left(c_{i}^{H}, \frac{y_{i}^{H}}{f\left(a_{i}, G^{F B}\right)}\right),
$$

where $G^{F B}$ satisfies Proposition $1, c_{i}=y_{i}$ (there are no taxes), and the $H$ superscript denotes the "hypothetical" free public goods scenario.

To calculate utility levels, we need to specify the utility functional form. We assume the following familiar specification (which is consistent with Mill's 1871 discussion of marginal utility above a minimum income).

$$
U\left(c_{i}, l_{i}\right)=\ln \left(c_{i}\right)-\frac{1}{\sigma}\left(\frac{y_{i}}{f\left(a_{i}, G\right)}\right)^{\sigma},
$$

so the individual's optimality condition in the hypothetical state is simply:

$$
c_{i}^{H}=y_{i}^{H}=f\left(a_{i}, G^{F B}\right),
$$

and utility levels in the hypothetical free public goods state are:

$$
U\left(c_{i}^{H}, l_{i}^{H}\right)=\ln \left(c_{i}^{H}\right)-\frac{1}{\sigma}\left(\frac{y_{i}^{H}}{f\left(a_{i}, G^{F B}\right)}\right)^{\sigma} .
$$

Finally, sacrifice for individual $i$ at the First-Best Lindahl Equilibrium allocation $\left\{c_{i}^{F B}, y_{i}^{F B}, G^{F B}\right\}$ is:

$$
S_{i}^{F B}=U\left(c_{i}^{H}, l_{i}^{H}\right)-U\left(c_{i}^{F B}, l_{i}^{F B}\right) .
$$

With these, we can show the following result.

Proposition 3 If $\left\{\left\{\tau_{i}^{F B}\right\}_{i}, G^{F B}\right\}$ is a First-Best Lindahl Equilibrium, the utility function takes the form in (12), and the ability production function is log-linear in public goods, that is, of the form $f\left(a_{i}, G\right)=h\left(a_{i}\right) G^{\gamma}$ for some differentiable function $h\left(a_{i}\right) ; \mathbb{R}^{+} \rightarrow \mathbb{R}^{+}$and $\gamma>0$, then $S_{i}^{F B}=S_{j}^{F B}$ for all types $i, j$ : that is, the policy generates equal sacrifice for all individuals.

It is important to note that this exact equivalence result holds only under a special set of functional form assumptions. Nevertheless, because those assumptions are familiar and arguably plausible, the connection in Proposition 3 hints at more than a superficial relationship. In particular, it suggests that two of the most prominent alternatives to the conventional social welfare maximization criterion-the CBBT logic of Smith (1776) and the equal sacrifice logic of Mill (1871)push optimal policy in a similar direction away from the conventionally-optimal design. Consistent with this finding is the observation that Mill, who rejected benefit-based taxation in favor of equal sacrifice taxation, nevertheless endorsed a similar tax schedule as Smith and invoked Smith as inspiration for his reasoning. ${ }^{19}$ Therefore, to the extent that either of these principles presents a plausible alternative-from either a positive or a normative perspective-to the conventional approach, this connection may strengthen the claims of the other.

\footnotetext{
${ }^{19}$ Both endorsed proportional taxation above a minimum level of income.
} 


\section{Quantitative characterization of constrained-optimal (second- best) classical benefit-based taxes}

A persistent critique of Lindahlian benefit-based reasoning (e.g., Mill 1871 and Samuelson 1954), is that individuals' benefits are unobservable. How to pursue benefit-based policy when constrained by this unobservability has been a topic of intense study for decades (e.g., Foley 1970). When one uses the classical view of benefit-based taxation, however, the problem of unobservable benefit is converted to the problem of unobservable ability-exactly the constraint at the heart of modern Mirrleesian tax theory. In this section, we take advantage of that feature of CBBT and use familiar methods to study constrained optimal benefit-based taxation. In particular, the purpose of this section is to understand how constrained-optimal benefit-based taxation responds quantitatively to the way in which public goods and endowed ability interact to produce income-earning ability. We consider illustrative cases of that interaction to show the wide variety of tax policies that may be consistent with classical benefit-based reasoning.

\subsection{Specifying the constrained planner's problem}

Like many alternatives to the standard welfarist objectives in modern optimal tax theory, the classical benefit-based principle does not rank allocations other than its most-preferred. As incentive constraints will force the policy away from its first-best optimum, we need to be able to complete this ranking to identify the second-best policy. The approach taken here applies a simplified version of the technique developed in Weinzierl (2014); see that paper for a more general approach.

To rank the set of feasible and incentive compatible allocations according to the classical benefitbased view, I specify an objective function that penalizes symmetric deviations from that principle's first-best allocation. ${ }^{20}$ I specify a simple version of such an objective function that nevertheless satisfies the Pareto criterion that allocations yielding greater utilities for some and no less utility for all are (at least weakly) preferred, thus avoiding the concerns of Kaplow and Shavell (2001). In particular, the objective function has a kink at its most-preferred allocation, so that the welfare loss due to a deviation below that allocation is greater than the welfare gain due to a similar-sized deviation above it.

Formally, recall the optimal feasible allocation that we derived and characterized in the previous section $\left\{c_{i}^{F B}, y_{i}^{F B}, G^{F B}\right\}_{i}$. The objective function, denoted $\mathcal{W}$, is defined as follows. ${ }^{21}$

$$
\mathcal{W}\left(\left\{c_{i}, y_{i}, G\right\}_{i},\left\{c_{i}^{F B}, y_{i}^{F B}, G^{F B}\right\}_{i}\right)=\sum_{i=1}^{I} V\left(U\left(c_{i}, \frac{y_{i}}{f\left(a_{i}, G\right)}\right), U\left(c_{i}^{F B}, \frac{y_{i}^{F B}}{f\left(a_{i}, G^{F B}\right)}\right)\right),
$$

where

$$
V\left(U_{i}, U_{i}^{F B}\right)=\left\{\begin{array}{c}
\delta\left(U_{i}-U_{i}^{F B}\right) \text { if } U_{i}^{F B}<U_{i} \\
\left(U_{i}-U_{i}^{F B}\right) \text { if } U_{i}^{F B} \geq U_{i}
\end{array},\right.
$$

for scalar $\delta: 0 \leq \delta \leq 1$.

\footnotetext{
${ }^{20}$ As far as I am aware, no previous work has studied how to obtain a complete ranking of allocations based on classical benefit-based reasoning (i.e., where benefits are linked to income-earning abilities). My approach is, therefore, by necessity somewhat speculative and future research may, of course, discover preferable alternative specifications.

${ }^{21}$ Readers familiar with Weinzierl (2014) will notice a strong similarity between the treatment of benefits-based taxation in this paper and Equal Sacrifice taxation in that paper. Though Section 1.3 showed that these criteria may yield quantitatively similar results in some cases, the similarity of treatment is not due to this connection but rather to the requirement of an objective function that punishes deviations from an optimal allocation but respects Pareto efficiency.
} 
The objective function in expressions (15) and (16) applies weight $\delta$, where $0 \leq \delta \leq 1$, to deviations of individual utility above the allocation $\left\{c_{i}^{F B}, y_{i}^{F B}, G^{F B}\right\}_{i}$. The asymmetric punishment of downward deviations from the benchmark allocation implied by (the strict case of) $\delta \leq 1$ rejects the utilitarian idea that the distribution of utility across individuals is irrelevant. The assumption that $\delta \geq 0$ respects a weak form of Pareto Efficiency ( $\delta>0$ would respect a strong form). Though the nondifferentiability caused by $\delta<1$ is technically inconvenient, it respects the classical benefitbased criterion's priorities. In contrast, a smooth loss function would imply local indifference to symmetric deviations from the most-preferred allocation, violating the principle that individuals who benefit equally from the activities of the state ought to pay equal taxes.

With this objective function, we can now state a planner's problem that closely mimics that of the conventional optimal tax model:

Problem 1 Classical benefit-based planner's problem:

$$
\max _{\left\{c_{i}, y_{i}, G\right\}_{i=1}^{I} \in\{\mathbb{F} \cap \mathbb{C}\}} \mathcal{W}\left(\left\{c_{i}, y_{i}, G\right\}_{i},\left\{c_{i}^{F B}, y_{i}^{F B}, G^{F B}\right\}_{i}\right)
$$

where $\mathcal{W}$ is defined in expressions (15) and (16), $\mathbb{F}$ denotes the set of feasible allocations for the economy:

$$
\mathbb{F}=\left\{\left\{c_{i}, y_{i}, G\right\}_{i=1}^{I}: \sum_{i=1}^{I}\left(y_{i}-c_{i}\right) \geq G\right\},
$$

and $\mathbb{I} \mathbb{C}$ denotes the set of incentive compatible allocations:

$$
\mathbb{I C}=\left\{\left\{c_{i}, y_{i}, G\right\}_{i=1}^{I}: U\left(c_{i}, y_{i} / f\left(a_{i}, G\right)\right) \geq U\left(c_{j}, y_{j} / f\left(a_{i}, G\right)\right) \text { for all } i, j \in\{1,2, \ldots, I\}\right\} .
$$

\subsection{Parameterization of the model, including the ability production function}

I assume a familiar form for the individual utility function, modified to include the effect of public goods on ability:

$$
U\left(c_{i}, y_{i} / f\left(a_{i}, G\right)\right)=\frac{1}{1-\psi}\left(c_{i}\right)^{1-\psi}-\frac{1}{\sigma}\left(\frac{y_{i}}{f\left(a_{i}, G\right)}\right)^{\sigma} .
$$

For this utility function, I assume $\psi=1.5$ and $\sigma=3$.

The novel specification required in this paper is how income-earning abilities are generated, that is, the form of the function $f\left(a_{i}, G\right)$. It is important to be clear that this paper does not base on direct empirical evidence its assumptions on the form of $f\left(a_{i}, G\right)$, though estimating such a relationship may be important for optimal tax analysis (both in this context and more generally). Instead, I will consider a flexible specification for $f\left(a_{i}, G\right)$ in order to illustrate the potential implications of the model. As will be clear, even a relatively simple but flexible specification is capable of yielding optimal policies that span a wide range of policy patterns (i.e., in terms of progressivity and the role of government). Those numerical findings are consistent with the perpetual uncertainty in benefit-based thinking over whether the rich or poor benefit more from public goods. One way to interpret a contribution of this paper is to put that debate into formal terms, clarifying the implicit conditions that resolve that uncertainty and making clear the empirical evidence required to resolve it.

Specifying $f\left(a_{i}, G\right)$ poses a number of challenges: it ought to produce plausible distributions of ability given a realistic value of $G$; it ought to allow endowed ability to be related to income-earning 
ability in a range of ways; and it ought to be as analytically simple and empirically applicable as possible.

To address these challenges, I map individuals' endowed types to fixed percentile positions in an ability distribution that is endogenous to the level of $G .{ }^{22}$ Specifically, I will assume that incomeearning ability is lognormally distributed and that the parameters of that distribution depend on the level of $G .^{23}$ Then, for any value of $G$, individual $i$ will have income-earning ability equal to the inverse cumulative distribution function (cdf) of the resulting income-earning distribution at $i$ 's fixed percentile position. Formally, we can write:

$$
P\left(a_{i}\right)=\Phi\left(\frac{\ln f\left(a_{i}, G\right)-\mu(G)}{\sigma(G)}\right),
$$

where $\Phi$ is the standard normal cdf, $P\left(a_{i}\right)$ is the percentile for type $a_{i}$, and where the mean $\mu(G)$ and standard deviation $\sigma(G)$ of the lognormal income-earning distribution depend on $G$. Income-earning ability can then be derived using the inverse cumulative distribution function and its parameters, so that for type $i$,

$$
\ln f\left(a_{i}, G\right)=\sigma(G) \Phi^{-1}\left[P\left(a_{i}\right)\right]+\mu(G),
$$

Note that this structure assumes that public goods do not affect the ordering of individuals in the ability distribution. While relaxing that assumption may be of interest, it is left for future work. One reason to assume that $f\left(a_{i}, G\right)$ is order-preserving, at least in the context of a positive optimal tax analysis, is that it may be difficult to convince most people of a specific alternative.

Lacking evidence on the forms of $\mu(G)$ and $\sigma(G)$, I assume the following simple forms:

$$
\begin{aligned}
\mu(G) & =\bar{\mu}-\frac{\xi}{G}+\ln G^{\gamma} \\
\sigma(G) & =\bar{\sigma}+\beta_{1} G+\beta_{2} G^{2},
\end{aligned}
$$

where $\xi, \gamma, \bar{\mu}$, and $\bar{\sigma}$ are constants.

Though simple, the forms assumed in (20) have a few appealing features.

First, this specification implies that all income-earning abilities approach zero as the state disappears (i.e., $\lim _{G \rightarrow 0} \mu(G)=-\infty$ because of the term $-\xi / G$ ). A degenerate ability distribution at zero is a natural starting point for analysis, as it addresses the classic critique of (non-classical) benefit-based theory: namely, that without a state income-earning abilities would be negligible (see Murphy and Nagel, 2003, p. 17).

Second, the specification lends itself to estimation with (time-series, cross-country, or panel) data on (per capita) government expenditure and the distributional parameters of empirical ability distributions. As the empirical viability of benefit-based taxation has always been considered an obstacle, specifications that might conceivably be taken to the data may be important.

Third, expression (20) implies that, for $\beta_{1}=\beta_{2}=0$, the ability production function approaches a familiar form as $\xi$ becomes small. That is,

$$
\lim _{\xi \rightarrow 0} f\left(a_{i}, G\right)=\eta\left(a_{i}\right) G^{\gamma}
$$

\footnotetext{
${ }^{22}$ The equality of opportunity literature, for instance Roemer (1998), has used a similar fixed-positions technique.

${ }^{23}$ Though the lognormal distribution is relatively simple, and therefore has the advantage of making clear the impact of $G$ on the distribution of abilities, income distributions are better described by so-called double-Pareto-lognormal (DPLN) distributions. Future research may fruitfully extend this analysis to that case.
} 
where $\eta\left(a_{i}\right)=\exp \left(\bar{\sigma} \Phi^{-1}\left(P\left(a_{i}\right)\right)+\bar{\mu}\right)$ is constant with respect to $G$. Expression (21) is the simple multiplicative form for which Corollaries 1 and 2 were derived in the previous section. In fact, this expression is log-linear in $G$, for which we derived the especially clean results that spending on public goods as a share of total output and the flat average tax rate are equal to $\gamma$. It may be interesting, and reassuring, to note the (informal) intuition of Smith (1776) was that a classical benefit-based logic would lead to just such a proportional tax. ${ }^{24}$

To demonstrate the range of potential optimal policies under CBBT, I construct three sets of parameter values that are consistent with the empirical status quo but that have dramatically different optimal policy implications. Specifically, I choose three sets of values of $\bar{\mu}, \xi, \gamma, \bar{\sigma}, \beta_{1}$, and $\beta_{2}$ so that the simulated economy in each case-assuming the status quo tax policy-will be a close match to the overall share of spending on public goods in total income and the mean and variance of a lognormal distribution fitted to the U.S. wage distribution. ${ }^{25}$ For status quo tax policy, I use an approximation of the current U.S. tax system with a flat tax rate of 40 percent and a lumpsum grant equal to the excess of tax revenue over government spending. To roughly calibrate the target ability distribution, I use data on reported annual earnings and hours (as well as sample weights) from the National Longitudinal Survey of Youth 1996 survey to calculate the distribution of wages, a standard (though imperfect) empirical proxy for ability. The lognormal distribution that provides the best fit to these calculated wages has a mean of 2.5 and a standard deviation of 0.7. Finally, U.S. national accounts show government spending to be approximately 7.6 percent of GDP.

Table 1 shows these three sets of parameter values. The first column shows what I call the "baseline" specification, where $\beta_{1}=\beta_{2}=0$ and thus $f\left(a_{i}, G\right)$ satisfies expression (21). The remaining columns of Table 1 show variations on the baseline scenario in bold. The second column of Table 1 shows an "Expansive State" specification in which the baseline value of $\bar{\mu}$ is decreased to allow for a larger $\gamma$. In this scenario, public goods have greater power to magnify endowed ability. In the third column, I return to the baseline values of $\bar{\mu}$, choose an intermediate value of $\gamma$, and relax the baseline assumption that $\beta_{1}$ and $\beta_{2}$ are zero, instead considering a case in which increases in $G$ are relatively more beneficial for workers with high endowed ability. Formally, to the extent that increases in $G$ raise $\sigma(G)$, those higher in the endowed ability distribution will benefit more from public goods. I label this scenario the "Progressive" case, where $\beta_{1}>0$ is partially offset by $\beta_{2}<0$, so that a finite (and reasonable) value for $G$ is chosen, and $\bar{\sigma}$ is smaller.

\footnotetext{
${ }^{24}$ Note that Smith does endorse progressive taxation more generally, largely out of concern for the very poor. This mixed perspective is exactly that generated by the positive optimal tax analysis in this paper, where a conventional utilitarian logic motivates redistribution but a classical benefits-based logic limits the extent of that redistribution and its associated progressivity. See also the earlier footnote on Smith's mixed normative reasoning.

${ }^{25}$ The simulation has a distribution of individuals (indexed by their percentile position in the endowed ability distribution) choose labor effort to maximize utility, taking into account the ability production function, flat tax rate, and share of $G$ in output.
} 
Table 1: Parameterizations of the ability production function

\begin{tabular}{crrr}
\hline \hline Parameter & 1 (Baseline) & 2 (Expansive State) & 3 (Progressive) \\
\hline $\bar{\mu}$ & 2.36 & $\mathbf{2 . 2 0}$ & 2.36 \\
$\xi$ & 0.01 & 0.01 & 0.01 \\
$\gamma$ & 0.076 & $\mathbf{0 . 1 5 2}$ & $\mathbf{0 . 1 1 4}$ \\
$\bar{\sigma}$ & 0.70 & 0.70 & $\mathbf{0 . 3 0}$ \\
$\beta_{1}$ & 0.00 & 0.00 & $\mathbf{0 . 0 6}$ \\
$\beta_{2}$ & 0.00 & 0.00 & $-\mathbf{0 . 0 0 1}$
\end{tabular}

Empirical targets under Status Quo tax policy

$\begin{array}{rrrr}\mu(G)=2.5 & 2.5 & 2.5 & 2.6 \\ \sigma(G)=0.7 & 0.7 & 0.7 & 0.7 \\ G / \sum_{i} y_{i} & 0.076 & 0.076 & 0.076\end{array}$

While all three sets of parameter values are consistent with the same size of government and shape of the ability distribution under an approximation of the status quo U.S. tax policy, they imply quite different constrained-optimal policies. To obtain those policies, we simulate the planner's problem in expressions (17), (18), and (19) with $\delta=0$, corresponding to a strict version of CBBT.

In Figure 1, we plot average tax rates along the ability distribution in the second-best optimal benefit-based policy for the three scenarios.

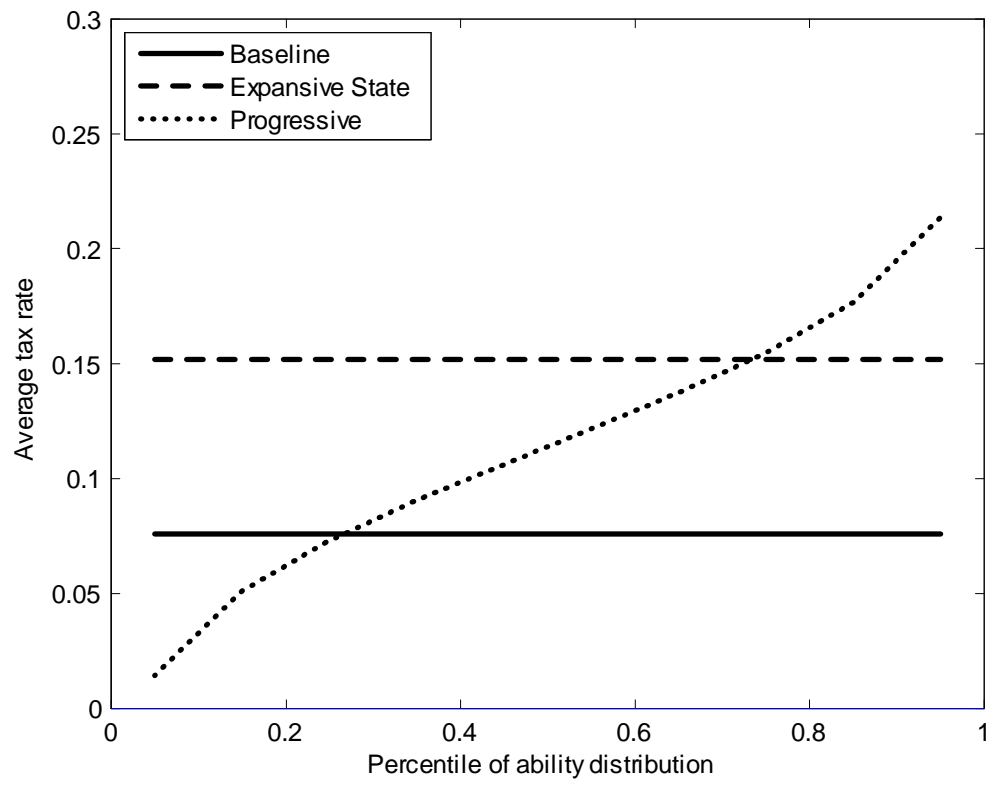

Figure 1: Average tax rates in the constrained-optimal policy under three sets of parameters from Table 1.

The message from these simulations is that optimal benefit-based taxation in its classical form can support a variety of sizes for government activity and a range of degrees of progressivity. That is, the shares of $G$ in total income in these three optimal policies are 7.6 percent, 15.2 percent, and 
11.8 percent, and the last of the three exhibits substantial progressivity. Benefit-based taxation is not necessarily "libertarian" in the sense of a minimal state; nor is it inconsistent with progressive taxation. $^{26}$

This flexibility is arguably behind CBBT's long-standing and apparently widespread appeal. As I show in a companion paper (Weinzierl 2015), support for CBBT among the public appears to be widespread and to cut across political and demographic categories. Rather than a niche principle to which a small group of iconoclasts subscribe, CBBT is a unifying idea that can be consistent with a range of views on both the impact of public goods spending on the ability distribution and, therefore, optimal government tax and expenditure policy more generally. ${ }^{27}$

That said, Figure 1 also shows that CBBT has sharp enough implications to inform the debate over optimal policy. First, disagreement over the incidence of benefits has a long history at the heart of the analysis of benefit-based taxation. The formalization of CBBT in this paper provides a way to discipline that debate and describe one's position in a more transparent, testable form. Second, optimal taxes under CBBT include negative average tax rates only if individuals are harmed by the activities of the state, an unlikely situation in modern developed economies. As a consequence, supporters of greater redistribution are less likely to support CBBT, and this feature of CBBT makes it easier for voters and policy makers to understand the positions they defend. As discussed at length in section 3, evidence suggests that a mixture of a non-redistributive principle such as CBBT with a redistributive principle such as utilitarianism is likely to provide the best description of the overall criterion that prevails in public judgments of tax policy. Understanding the implications of CBBT, both in general and given a specific ability production function, can help individuals decide what weight they put on the components of that mixture.

We can connect the results shown in Figure 1 to the analysis of first-best policy from Section 2 by calculating the realized values of the Hicksian partial elasticity of complementarity between public goods and endowed ability, $\theta_{i}^{G, a}$ as defined in expression (9). In Table 2 we show these values for the three cases plotted in Figure 1:

\begin{tabular}{lccc}
\hline \multicolumn{4}{l}{ Table 2: Hicksian partial elasticities of complementarity $\theta_{i}^{G, a}$} \\
\hline \hline $\begin{array}{l}\text { Percentile of } \\
\text { ability distrib. }\end{array}$ & 1 (Baseline) & 2 (Expansive State) & 3 (Progressive) \\
\hline 10 & 1.00 & 1.00 & 5.91 \\
30 & 1.00 & 1.00 & 1.82 \\
50 & 1.00 & 1.00 & 1.55 \\
70 & 1.00 & 1.00 & 1.43 \\
90 & 1.00 & 1.00 & 1.40 \\
\hline
\end{tabular}

As expected, the multiplicative form for the ability production function in the first two cases yields $\theta_{i}^{G, a}=1.00$ for all types, while case 3 shows that the progressivity of taxes is connected to the strong complementarity assumed between public goods and endowed ability in that case. To the extent that the Hicksian partial elasticity is a potential object of empirical study, it may therefore provide an important target for calibration exercises using this model.

\footnotetext{
${ }^{26}$ Both of these features are, in fact, consistent with Smith's view of taxation. Smith (1776) writes, "The third and last duty of the sovereign or commonwealth is that of erecting and maintaining those public institutions and those public works...necessary for the defence of the society, and for the administration of justice,...for facilitating the commerce of the society, and those for promoting the instruction of the people." Also see the earlier footnote on Smith's endorsement of progressivity.

${ }^{27}$ To take a specific example, both Barack Obama and Mitt Romney-who as shown in the Appendix express quite different views of the role of the state and optimal progressivity- invoked CBBT as justification for their positions in the 2012 U.S. presidential election.
} 


\section{Quantitative results under a mix of the classical benefit-based and utilitarian criteria for optimal taxes}

While the benefit-based criterion plays a prominent role in public rhetoric over taxation, it is unlikely to be the only principle that guides the design of taxes. In particular, the utilitarian criterion that dominates quantitative work in the optimal tax literature almost certainly plays a role-perhaps a very large role-in policy evaluation. The ubiquity of redistribution in advanced economies requires, given that benefit-based taxation is unlikely to recommend negative average tax rates on any individual, that some other principle exerts influence on policy; utilitarianism is a natural candidate for that alternative. In fact, the utilitarian logic is consistent with non-benefitbased arguments with which American politicians and analysts justify tax policy preferences, for instance when stressing the importance of helping the "needy" or those who are "struggling" to make necessary purchases. ${ }^{28}$

In this context it may be of interest that Richard Musgrave (in Buchanan and Musgrave, 1999), toward the end of an illustrious career as a scholar of taxation and the role of the state, wrote: "Moreover, observers such as myself who tend to be egalitarian should not rule out the norm of Lockean entitlement to earnings (Locke [1690]; 1960; Nozick 1974) as an alternative criterion that deserves consideration. Most people, I suggest, would wish to assign some weight to both norms...I also think that entitlement to earnings, the Lockean and Adam Smith tradition, has its merit. I would give it, say, one-quarter weight with three-quarters to the Rawlsian concept."

In this section, I demonstrate that an objective for taxation that incorporates both the classical benefit-based and utilitarian criteria can, as this discussion suggests, yield optimal policies consistent with important features of existing policy. The first step in that demonstration is to show how such a mixed objective can be formalized.

\subsection{Formalizing a mixed objective function}

To combine CBBT and utilitarianism into one objective, I take advantage of a convenient feature of the formalization of the classical benefit-based planner's problem in expressions (17), (18), and (19). Recall that, in that problem, the planner's desire to stay near the first-best benefit-based allocation is constrained not only by feasibility and incentive compatibility but also by Pareto efficiency. As discussed earlier, the Pareto efficiency requirement is included by having the planner's objective not only punish deviations of individuals' utilities below their benchmark levels but also reward (at least weakly) deviations of individuals' utilities above those levels. Formally, in expression (16), we assume that $\delta \geq 0$.

The extreme values for $\delta$ imply an objective based on only one principle. In the previous section, for example, we simulated constrained-optimal benefit-based taxation by assuming $\delta=0$, implying a strict commitment on the part of the planner to the classical benefit-based criterion. At the other extreme, when $\delta=1$, the planner's objective is equivalent to the conventional utilitarian objective to maximize the unweighted sum of individual utilities. To see this, impose $\delta=1$ on expression (16) to obtain $V\left(U_{i}^{F B}, U_{i}\right)=U_{i}^{F B}-U_{i}$, so that the objective function in expression (15) simplifies to $\mathcal{W}(\cdot)=\sum\left(U_{i}-U_{i}^{F B}\right)$, and the planner's objective (17) becomes

\footnotetext{
${ }^{28}$ At the same time, redistribution-a key source of welfare gains in the standard approach-is often explicitly rejected as a justification for tax policy, even by policymakers who might be expected to support it. For example, the statement by President Obama given in the Introduction includes the claim that "everybody pays." Also consider a statement he made in 2012: "So when we have debates now about our tax policy, when we have debates now about the Buffett rule that we've been talking about, where we say if you make a million dollars a year or more you shouldn't pay a lower tax rate than your secretary, that is not an argument about redistribution. That is an argument about growth."
} 
$\max _{\left\{c_{i}, y_{i}, G\right\}_{i=1}^{I} \in\{\mathbb{F} \cap \mathbb{I C}\}} \sum\left(U_{i}-U_{i}^{F B}\right)$. Because the allocations $U_{i}^{F B}$ do not depend on the chosen allocation $\left\{c_{i}, y_{i}, G\right\}_{i=1}^{I}$, this objective is equivalent to: $\max _{\left\{c_{i}, y_{i}, G\right\}_{i=1}^{I} \in\{\mathbb{F} \cap \mathbb{I} \mathbb{C}\}} \sum U_{i}$, the utilitarian planner's objective.

Intermediate values of the parameter $\delta$ provide, therefore, a simple way to form an objective function that lies between-in a formal sense-the classical benefit-based and utilitarian principles.

\subsection{Features of optimal policy under a mixed objective}

We now show, briefly, how varying $\delta$ can yield a wide range of optimal policy results. Most important, we show that optimal policy computed with certain values for $\delta$ can match several arguably important features of existing policy that are difficult to reconcile in the conventional model (where $\delta=1$ ).

Progressivity First, I consider optimal average tax rate schedules for a calibrated U.S. ability distribution. I discretize (into 50 types) the ability distribution obtained as the "baseline" case from Table 1 for the values of $\bar{\mu}, \xi, \gamma, \bar{\sigma}, \beta_{1}$, and $\beta_{2}$ : this was the set of parameters that yielded a small government with a flat average tax rate as constrained-optimal in the previous section. Figure 2 shows the average tax rate results for four values of $\delta$ :

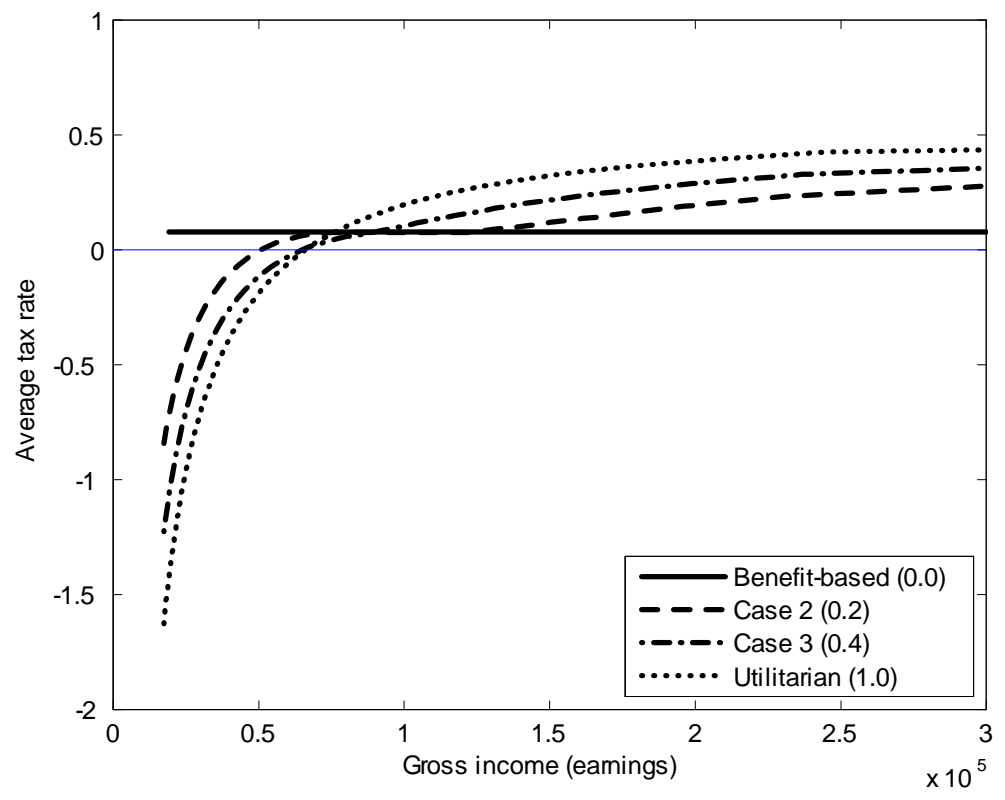

Figure 2: Average tax rates for four values of $\delta$ (in parentheses), assuming the baseline ability production function.

As this figure shows, the extent of progressivity in the optimal policy is reduced when the classical benefit-based criterion receives greater weight in the objective function (under the baseline specification of the ability production function).

The average tax rate paid by high earners in the conventional utilitarian policy shown in Figure 2 is 46 percent, while the Congressional Budget Office reports that the average federal tax rate 
(including all federal taxes) averaged 30 percent from 2000 through 2010. Though the gap between those figures has many possible explanations, note that the average tax rates assessed under the mixed cases (2 and 3 ) in Figure 2 are 31 and 39 percent, substantially closer to what prevails in current U.S. policy.

As for low earners, the CBBT and utilitarian criteria yield sharply conflicting recommendations, with negative average tax rates implied for $0,31,47$, and 57 percent of the population in the four cases shown in Figure 2. The average tax rates at the 10th percentile of the simulated distribution are approximately 7, -40, -80, and -140 percent, while in reality the CBO reports that in 2011 the lowest earning quintile of Americans received net income (after taxes and transfers) 55 percent greater than their market income (before taxes and transfers). As with the comparison of taxes on high earners, these rough comparisons suggest that the mixed cases (2 and 3) in Figure 2 provide a relatively good fit with existing U.S. tax policy.

Rank reversals in utility Second, I consider the distribution of utility levels under the optimal policy in a first-best setting. As has been known since Mirrlees (1971), the first-best utilitarian tax policy recommends that income-earning ability be inversely related to utility levels. That is, consumption is equalized across types, but those with higher income-earning ability are required to exert more labor effort. While the second-best optimal policy cannot achieve such "rank reversals," many commentators have argued that prevailing norms about economic justice would reject the idea that an unconstrained optimal policy would include them (see, for example, King 1983 and Saez and Stantcheva 2015).

The concern over rank reversals relates directly to the "endowment taxation" nature of the conventional modern approach to optimal taxation. Philosophers and legal scholars have extensively analyzed this issue (for instances of the latter, see Hasen (2007), Markovits (2003), Rakowski (2000), Shaviro (2002), Stark (2005), Sugin (2011), and Zelenak (2006)). Rawls (2001) himself worried that an endowment tax "would force the more able into those occupations in which earnings were high enough for them to pay off the tax in the required period of time; it would interfere with their liberty to conduct their life within the scope of the principles of justice." ${ }^{29}$ The wide-ranging affinity for this critique is apparent when Rawls' warning is coupled with Robert Nozick's (1974) claim that "taxation of earnings from labor is on a par with forced labor" because "it is like forcing the person to work $n$ hours for another's purpose." 30

To examine the effect of using a mixed objective on the appeal of rank reversals, Figure 3 shows the utility levels achieved by all ability types under the first-best policies in the same four cases as were used to produce Figure 2.

\footnotetext{
${ }^{29}$ Also see Richard Arneson (2000), who writes: "It is better to regard Rawls as making the point that ...it is a flaw that utilitarianism would have the decision about what should be done vary only with the utility total that different acts could achieve."

${ }^{30}$ Stark (2005) offers a detailed argument that the concerns of Rawls and Nozick are closely connected.
} 


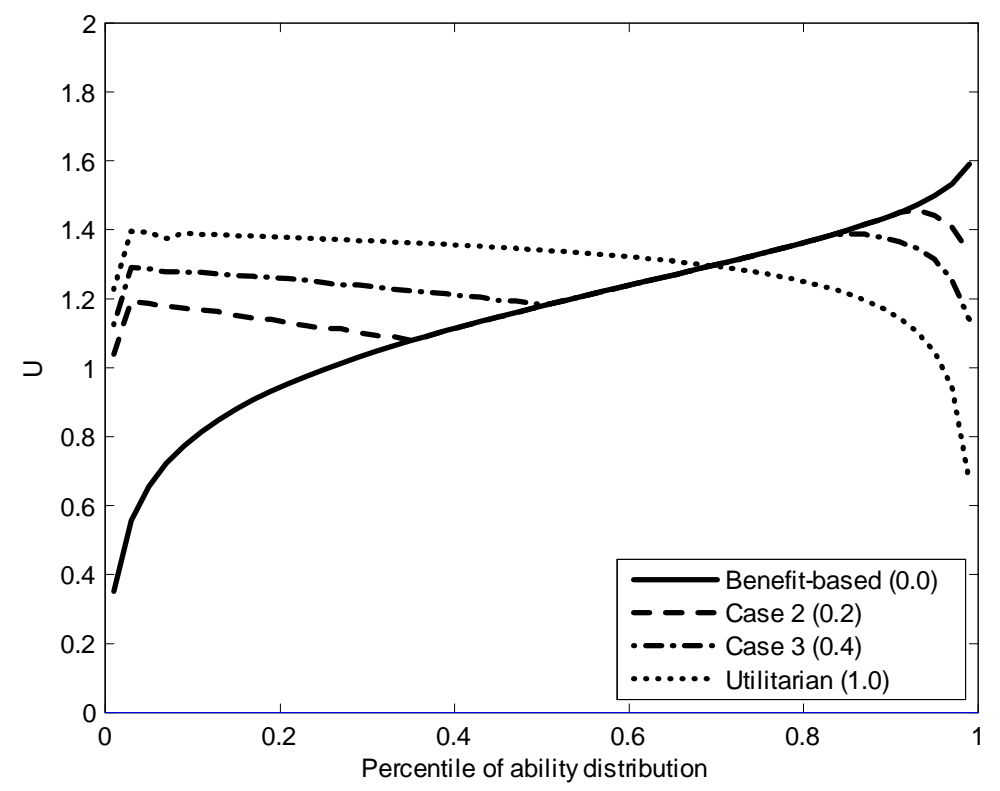

Figure 3: Utility levels by ability type in the first-best (full information) optimal allocations for four values of $\delta$ (shown in parentheses), assuming the baseline ability production function

As this figure shows, the pure utilitarian objective puts in place substantial rank reversals, while the strict benefit-based case has utility positively related to ability in the first-best. Intermediate cases temper the rank reversals of the utilitarian approach.

Tagging Finally, I consider the implications of a mixed criterion for the taxation of personal characteristics, otherwise known as tagging (following Akerlof 1978). In Mankiw and Weinzierl (2009) and Weinzierl (2014), it is shown that a conventional utilitarian optimal policy would levy substantially greater tax rates on some demographic groups in the United States relative to others. In fact, in the modern theory of optimal taxation, tagging is a free lunch, and a wide variety of candidate tags exist. Any observable and largely inelastic characteristic across which the distribution of abilities differs ought to affect tax schedules. These conclusions stand in stark contrast to the limited extent of tagging in actual policy. The few examples of existing tagging bear little resemblance to the broad and nuanced application recommended by modern optimal tax theory.

In Weinzierl (2014), a mixed normative criterion that blends utilitarianism with some (empiricallygrounded) weight on Mill's principle of Equal Sacrifice is shown to diminish optimal tagging of these characteristics dramatically and-crucially-much more than it diminishes optimal redistribution.

In this subsection, I find a similar result when the objective function blends utilitarianism with the principle of benefit-based taxation and the effects of public goods on ability are assumed to be independent of the tagged characteristics. The commonality of results across this paper and Weinzierl (2014) is related to the connection shown between CBBT and Equal Sacrifice above.

To show this result, I assume that three tagged groups have different values for the parameters $\mu(G)$ and $\sigma(G)$ in the ability production function (20). The ability distributions for these three 
groups are shown in Figure 4.

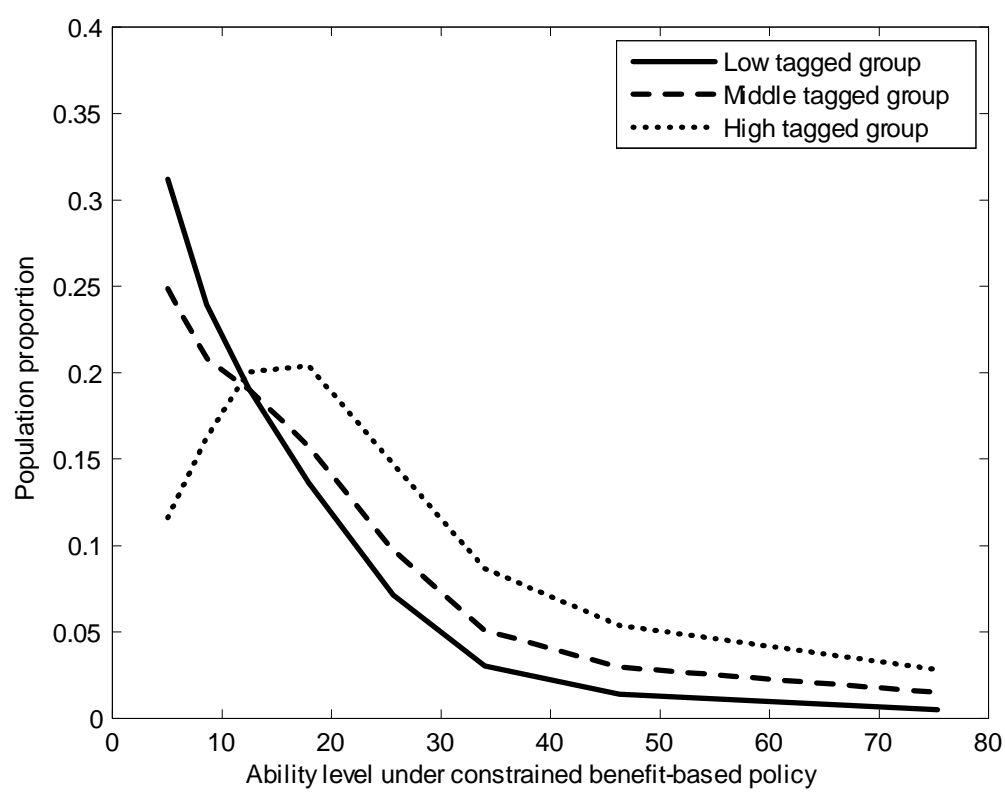

Figure 4: Ability distributions for three tagged groups.

Based on the distributions in Figure 4, a utilitarian criterion will recommend tagging: e.g., taxing a member of the "High" group more than a member of the "Low" group who has the same incomeearning ability. On the other hand, CBBT will not endorse tagging, because individuals with the same ability levels have all benefited equally from the activities of the state, regardless of their tagged group (by assumption).

By varying the value of $\delta$, we can compare the extent of tagging pursued by planners with different weights on the classical benefit-based criterion relative to conventional utilitarianism. I measure the extent of tagging by calculating the total extra taxes paid (or transfers received) by a tagged group, as a share of that group's total income, when a planner initially not allowed to tag is given the power to do so (i.e., to make a person's tax payments depend on which tagged group they belong to). Table 3 shows these tagging results for the same set of values of $\delta$ in expression (16) as were used to generate Figures 2 and 3. It also shows the maximum average tax rate assessed in each simulation.

\begin{tabular}{ccccccc}
\hline \multicolumn{6}{c}{ Table 3: Extent of Tagging (Extra tax or transfer rate, in percent) } \\
\hline \hline & $\delta$ & Low & $\begin{array}{c}\text { Tagged group } \\
\text { Middle }\end{array}$ & High & Max ATR \\
\hline Benefit-based & 0 & 0.1 & 0.0 & -0.1 & 8.2 \\
Case 2 & 0.20 & -0.2 & 0.0 & 0.2 & 33.2 \\
Case 3 & 0.40 & -2.5 & 0.4 & 0.6 & 42.6 \\
Utilitarian & 1.00 & -9.8 & -2.0 & 7.8 & 54.3 \\
\hline
\end{tabular}

As this table shows, the extent of tagging falls dramatically in Case 3 and especially Case 2 relative to the utilitarian benchmark (Case 4), while the progressivity of the tax schedule diminishes much less. In words, these results show that an objective for optimal policy that gives weight to 
the classical benefit-based criterion as well as utilitarianism can reconcile prevailing policy's limited use of tagging and substantial progressivity.

It is important to clarify that the opposition to tagging under the classical benefit-based criterion depends on the assumption that the effects of public goods are independent of the tagged characteristic. If they are not-for example if some groups are advantaged more than others by biased public goods provision-then classical benefit-based taxation would recommend taxing based on those characteristics (i.e., tagging). This subtlety is consistent with policies-such as Affirmative Action in the United States-that are designed to offset the disparities in how endowed ability is translated into income-earning ability across demographic groups.

\section{Conclusion}

In this paper, I have explored whether we might incorporate into modern tax theory a logic for tax design that appears to play a role in public reasoning but that has been largely set aside by theorists. The idea that an individual ought to pay taxes based on the benefit he or she derives from the public goods the government produces has been, for many centuries, an intuitively compelling one. I marry that intuition to two ideas: first, Adam Smith's "classical" view that the best measure of that benefit is a person's income-earning ability; and second, the plausible assumption that an individual's income-earning ability is a function of both endowed ability and public goods.

As a result, classical benefit-based taxation turns out to fit seamlessly into a generalized version of the standard Mirrleesian model. I apply Lindahl's approach to assigning taxes based on marginal benefit in that model, and show that we can use familiar modern methods to characterize firstbest policy analytically and second-best policy quantitatively. Moreover, the required components of the model are, at least in principle, amenable to empirical analysis using standard data and straightforward elasticities.

Simulations of optimal policy in this model, using an objective function that gives weight to both the conventional utilitarian criterion and the classical benefit-based view, can yield policies that match well several features of existing policy that are difficult to reconcile under the conventional objective. To the extent that such a mixed criterion is a good approximation of prevailing objectives for tax policy, this model may offer a useful approach to positive optimal tax theory. 


\section{Appendix}

\subsection{Classical benefit-based reasoning in American political rhetoric}

This brief section highlights additional instances in which prominent policymakers or policy commentators have relied on the classical logic of benefit-based taxation in their discussions of tax policy.

In the 2012 U.S. Presidential election, a fierce debate erupted over the following remarks made by President Obama.

There are a lot of wealthy, successful Americans who agree with me - because they want to give something back. They know they didn't — look, if you've been successful, you didn't get there on your own....Somebody helped to create this unbelievable American system that we have that allowed you to thrive. Somebody invested in roads and bridges. If you've got a business - you didn't build that. Somebody else made that happen.

The Republican nominee for president, former Massachusetts Governor Mitt Romney, seized on the remark and responded:

He [Obama] said this, "If you've got a business, you didn't build that. Somebody else made that happen." That somebody else is government, in his view. He goes on to describe the people who deserve the credit for building this business. And, of course, he describes people who we care very deeply about, who make a difference in our lives: our school teachers, firefighters, people who build roads. We need those things. We value school teachers, firefighters, people who build roads. You really couldn't have a business if you didn't have those things. But, you know, we pay for those things. Alright? The taxpayers pay for government. It's not like government just provides those to all of us and we say, "Oh, thank you government for doing those things." No, in fact, we pay for them and we benefit from them and we appreciate the work that they do and the sacrifices that are done by people who work in government. But they did not build this business.

The important feature of this exchange, for the purposes of this paper, is that Obama and Romney agree that public goods are essential for production and that the individuals who benefit from them ought to pay for them. Both, in other words, appear to support the classical view of benefit-based taxation. ${ }^{31}$

Examples of affinity for the classical view come not only from politicians and economists. Warren Buffett is a prominent American investor and policy advisor behind the so-called "Buffett Rule" that would set a floor on the average tax rate paid by high income earners. For many years, Buffett has argued for higher taxes on the rich with the metaphor he calls the Ovarian Lottery, as in the following statement.

\footnotetext{
${ }^{31}$ In fact, the disagreement between the candidates' positions appears still narrower when one considers that the Obama campaign later asserted that the President had been referring to roads and bridges, not the business, when he said "you didn't build that." That is, both Obama and Romney appear to grant individuals' some moral claim to their income. That position is consistent with the classical benefit based logic but in contrast with the conventional Mirrleesian model, as the latter is based on a Rawlsian framework in which individuals do not have such a claim-see Fleurbaey and Maniquet (2006) for more discussion.
} 
"Imagine there are two identical twins in the womb, both equally bright and energetic. And the genie says to them, 'One of you is going to be born in the United States, and one of you is going to be born in Bangladesh. And if you wind up in Bangladesh, you will pay no taxes. What percentage of your income would you bid to be the one that is born in the United States?' It says something about the fact that society has something to do with your fate and not just your innate qualities. The people who say, 'I did it all myself,' and think of themselves as Horatio Alger - believe me, they'd bid more to be in the United States than in Bangladesh. That's the Ovarian Lottery."

Buffett's concept of the ovarian lottery reflects an affinity for both the Rawlsian normative view that lies behind the social welfare maximization approach of Mirrleesian optimal tax theory and the classical view of benefit-based taxation. First, the ovarian lottery is a close cousin of Rawls' veil of ignorance, and in other contexts Buffett directly endorses the idea that combining such a view with the assumption of diminishing marginal utility of income generates a reason-in fact the reason in the standard model-for income redistribution. ${ }^{32}$ The remarkable aspect of Buffett's reasoning, for this paper's purposes, is that it also draws so directly on the benefit-as-ability logic for taxation. It seems that Buffett, like most people, has a multifaceted normative perspective on optimal tax design.

\subsection{Proofs of Proposition 1 and Corollary 1}

Use the second and third FOCs to set

$$
\frac{y_{i} f_{G}\left(a_{i}, G_{i}\right)}{f\left(a_{i}, G_{i}\right)} \frac{1}{p}=\tau_{i}
$$

Use $\sum_{i \in I} \tau_{i}=1$ to obtain

$$
\sum_{i \in I} \frac{y_{i} f_{G}\left(a_{i}, G_{i}\right)}{f\left(a_{i}, G_{i}\right)}=p
$$

At the Lindahl optimum, $G_{i}=G_{j}=G^{*}$ for all types, so that

$$
\sum_{i \in I} \frac{y_{i} f_{G}\left(a_{i}, G^{*}\right)}{f\left(a_{i}, G^{*}\right)}=p .
$$

Now, note that the MRS for individual $i$ when $G_{i}=G_{j}=G^{*}$ for all types is:

$$
\frac{\frac{-y_{i} f_{G}\left(a_{i}, G^{*}\right)}{f\left(a_{i}, G^{*}\right)} \frac{1}{f\left(a_{i}, G_{i}\right)} u_{l}\left(c_{i}, \frac{y_{i}}{f\left(a_{i}, G\right)}\right)}{u^{\prime}\left(c_{i}\right)}
$$

or, using the first and second FOCs, this simplifies to:

$$
\frac{y_{i} f_{G}\left(a_{i}, G^{*}\right)}{f\left(a_{i}, G^{*}\right)} \text {. }
$$

Using (22), take the sum across $i$ to obtain the result, imposing that $G_{i}=G_{j}=G^{*}$ for all types.

To prove the corollary, use the expression

$$
f_{G}\left(a_{i}, G^{*}\right)=\gamma a_{i}^{\alpha} G^{\gamma-1}
$$

in the result from the Proposition and simplify.

\footnotetext{
${ }^{32}$ See, for example, Buffett's entry at the Giving Pledge: http://cms.givingpledge.org/. While Buffett, there, is speaking of voluntary redistribution, his advocacy for more progressive taxation suggests he would go beyond that.
} 


\subsection{Proofs of Proposition 2 and Corollary 2}

Using the expression for individual taxes, we can express the average tax rate for individual $i$ as:

$$
A T R_{i}=\frac{\tau_{i} p G^{*}}{y_{i}}=\frac{f_{G}\left(a_{i}, G^{*}\right)}{f\left(a_{i}, G^{*}\right)} G^{*}
$$

Take the derivative with respect to $a_{i}$ to obtain

$$
\frac{\partial A T R_{i}}{\partial a_{i}}=\frac{f\left(a_{i}, G^{*}\right) f_{G, a}\left(a_{i}, G^{*}\right)-f_{G}\left(a_{i}, G^{*}\right) f_{a}\left(a_{i}, G^{*}\right)}{f\left(a_{i}, G^{*}\right) f\left(a_{i}, G^{*}\right) / G^{*}} .
$$

The denominator is positive, so the sign is determined by the numerator. It is positive iff:

$$
f\left(a_{i}, G^{*}\right) f_{G, a}\left(a_{i}, G^{*}\right)>f_{G}\left(a_{i}, G^{*}\right) f_{a}\left(a_{i}, G^{*}\right)
$$

We assume all (single) partials are positive, so this can be written as

$$
\frac{f_{G, a}\left(a_{i}, G^{*}\right)}{f_{G}\left(a_{i}, G^{*}\right)}>\frac{f_{a}\left(a_{i}, G^{*}\right)}{f\left(a_{i}, G^{*}\right)}
$$

which gives the first condition. Now, the sign is negative iff

$$
f\left(a_{i}, G^{*}\right) f_{G, a}\left(a_{i}, G^{*}\right)<f_{G}\left(a_{i}, G^{*}\right) f_{a}\left(a_{i}, G^{*}\right) .
$$

Again, assuming all single partials are positive, this yields the second condition:

$$
\frac{f_{G, a}\left(a_{i}, G^{*}\right)}{f_{G}\left(a_{i}, G^{*}\right)}<\frac{f_{a}\left(a_{i}, G^{*}\right)}{f\left(a_{i}, G^{*}\right)} .
$$

To prove the corollary, substitute the Cobb-Douglas function into the average tax rate expression and simplify.

\subsection{Proof of Proposition 3}

The optimal level of public goods is $G^{*}=\frac{\gamma}{p} \sum_{i \in I} y_{i}$. In the hypothetical allocation with no taxes, the individual sets

$$
c_{i}=y_{i}=h\left(a_{i}\right)\left(G^{*}\right)^{\gamma}=h\left(a_{i}\right)\left(\frac{\gamma}{p} \sum_{i \in I} y_{i}\right)^{\gamma} \text {, }
$$

so utility is

$$
U\left(c_{i}, l_{i}\right)=\ln \left(h\left(a_{i}\right)\left(\frac{\gamma}{p} \sum_{i \in I} y_{i}\right)^{\gamma}\right)-\frac{1}{\sigma} .
$$

In the actual optimal allocation, with costly public goods, Corollary 2 showed that $A T R_{i}=$ $\tau_{i} p G^{*} / y_{i}=\gamma$. Individuals set

$$
\begin{aligned}
\frac{1}{c_{i}} & =\lambda \\
\frac{1}{h\left(a_{i}\right) G^{\gamma}}\left(\frac{y_{i}}{h\left(a_{i}\right) G^{\gamma}}\right)^{\sigma-1} & =\lambda \\
\gamma \frac{1}{G}\left(\frac{y_{i}}{h\left(a_{i}\right) G^{\gamma}}\right)^{\sigma} & =\tau_{i} p \lambda
\end{aligned}
$$


Combining the second and third,

$$
y_{i}=\frac{\tau_{i} p G^{*}}{\gamma}
$$

Combining this with the first and second,

$$
\frac{1}{c_{i}}=\left(\frac{1}{h\left(a_{i}\right)}\right)^{\sigma}\left(\frac{\tau_{i} p}{\gamma}\right)^{\sigma-1} G^{\sigma(1-\gamma)-1}
$$

which, into the budget constraint, gives

$$
G=\left(\frac{h\left(a_{i}\right) \gamma^{\frac{\sigma-1}{\sigma}}}{\tau_{i} p}\left(\frac{\gamma}{1-\gamma}\right)^{\frac{1}{\sigma}}\right)^{\frac{1}{1-\gamma}}
$$

Rearrange to isolate the tax share:

$$
\tau_{i}=\frac{1}{p} \frac{h\left(a_{i}\right) \gamma^{\frac{\sigma-1}{\sigma}}}{G^{1-\gamma}}\left(\frac{\gamma}{1-\gamma}\right)^{\frac{1}{\sigma}} .
$$

Then use the budget constraint on tax shares to solve for $G$

$$
1=\frac{1}{p} \frac{\gamma^{\frac{\sigma-1}{\sigma}}}{G^{1-\gamma}}\left(\frac{\gamma}{1-\gamma}\right)^{\frac{1}{\sigma}} \sum_{i \in I} h\left(a_{i}\right) .
$$

and thus

$$
G=\left(\frac{1}{p} \gamma^{\frac{\sigma-1}{\sigma}}\left(\frac{\gamma}{1-\gamma}\right)^{\frac{1}{\sigma}} \sum_{i \in I} h\left(a_{i}\right)\right)^{\frac{1}{1-\gamma}}
$$

so

$$
\tau_{i}=\frac{h\left(a_{i}\right)}{\sum_{i \in I} h\left(a_{i}\right)},
$$

which is a nice side result that the tax share is the share of scaled endowed ability. Now we can solve for allocations.

$$
\begin{gathered}
y_{i}=\frac{\tau_{i} p\left(\frac{1}{p} \gamma^{\frac{\sigma-1}{\sigma}}\left(\frac{\gamma}{1-\gamma}\right)^{\frac{1}{\sigma}} \sum_{i \in I} h\left(a_{i}\right)\right)^{\frac{1}{1-\gamma}}}{\gamma} \\
c_{i}=\left(h\left(a_{i}\right)\right)^{\sigma}\left(\frac{\gamma}{\tau_{i} p}\right)^{\sigma-1}\left(\frac{1}{p} \gamma^{\frac{\sigma-1}{\sigma}}\left(\frac{\gamma}{1-\gamma}\right)^{\frac{1}{\sigma}} \sum_{i \in I} h\left(a_{i}\right)\right)^{\frac{1-\sigma(1-\gamma)}{1-\gamma}}
\end{gathered}
$$

and utility is

$$
\begin{gathered}
U\left(c_{i}, l_{i}\right)^{*}=\ln \left(h\left(a_{i}\right)\left(\frac{\gamma}{p} \sum_{i \in I} h\left(a_{i}\right)\right)^{\frac{\gamma}{1-\gamma}}\left(\left(\frac{1}{1-\gamma}\right)^{\frac{1}{\sigma}}\right)^{\frac{1-\sigma(1-\gamma)}{1-\gamma}}\right)-\frac{1}{\sigma} \frac{1}{1-\gamma} . \\
U\left(c_{i}, l_{i}\right)^{*}=\ln \left(h\left(a_{i}\right)\left(\frac{\gamma}{p} \sum_{i \in I} h\left(a_{i}\right)\right)^{\frac{\gamma}{1-\gamma}}(1-\gamma)^{1-\frac{1}{\sigma(1-\gamma)}}\right)-\frac{1}{\sigma} \frac{1}{1-\gamma} .
\end{gathered}
$$


vS.

$$
U\left(c_{i}, l_{i}\right)=\ln \left(h\left(a_{i}\right)\left(\frac{\gamma}{p} \sum_{i \in I} h\left(a_{i}\right)\right)^{\frac{\gamma}{1-\gamma}}\left(\left(\frac{1}{1-\gamma}\right)^{\frac{1}{\sigma}}\right)^{\frac{\gamma}{1-\gamma}}\right)-\frac{1}{\sigma}
$$

Sacrifice is, therefore:

$$
\begin{aligned}
U\left(c_{i}, l_{i}\right)-U\left(c_{i}, l_{i}\right)^{*}= & \ln \left(h\left(a_{i}\right)\left(\frac{\gamma}{p} \sum_{i \in I} h\left(a_{i}\right)\right)^{\frac{\gamma}{1-\gamma}}\left(\left(\frac{1}{1-\gamma}\right)^{\frac{1}{\sigma}}\right)^{\frac{\gamma}{1-\gamma}}-\frac{1}{\sigma}(29)\right. \\
& -\ln \left(h\left(a_{i}\right)\left(\frac{\gamma}{p} \sum_{i \in I} h\left(a_{i}\right)\right)^{\frac{\gamma}{1-\gamma}}\left(\left(\frac{1}{1-\gamma}\right)^{\frac{1}{\sigma}}\right)^{\frac{1-\sigma(1-\gamma)}{1-\gamma}}\right)-\frac{1}{\sigma} \frac{1}{1-\gamma}(30)
\end{aligned}
$$

or

$$
U\left(c_{i}, l_{i}\right)-U\left(c_{i}, l_{i}\right)^{*}=\frac{\sigma-1}{\sigma} \ln \left(\frac{1}{1-\gamma}\right)+\frac{1}{\sigma} \frac{\gamma}{1-\gamma}
$$

which is constant across types. 


\section{References}

[1] Aaron, Henry and M. McGuire, (1970). "Public Goods and Income Distribution," Econometrica, 38.

[2] Aaron, Henry and M. McGuire (1976), "Reply to Geoffrey Brennan," Econometrica, 44.

[3] Arneson, Richard J. (2000). "Rawls versus utilitarianism in the light of political liberalism," The Idea of a Political Liberalism: Essays on Rawls. Lanham MD: Rowman and Littlefield.

[4] Atkinson, Anthony and Joseph Stiglitz (1980) Lectures in Public Economics, New York: McGraw-Hill.

[5] Best, Michael and Henrik Kleven (2013), "Optimal Income Taxation with Career Effects of Work Effort," Working Paper.

[6] Blakey, Roy G. (1914). "The New Income Tax," American Economic Review, 4(1), March.

[7] Boadway, Robin (2012). From Optimal Tax Theory to Tax Policy. Cambridge:MIT Press.

[8] Bovenberg, L. and B. Jacobs, (2011)."Optimal Taxation of Human Capital and the Earnings Function," Journal of Public Economic Theory, 13(6).

[9] Brennan, H. G. (1976). " "On the Distributional Implications of Public Goods," Econometrica, 44.

[10] Brennan, H. G. (1976). "A Rejoinder to the Aaron-McGuire Reply," Econometrica, 44.

[11] Buchanan, James and Richard Musgrave (1999). Public Finance and Public Choice: Two Contrasting Visions of the State, CESifo

[12] Feldstein, Martin (1976). "On the Theory of Tax Reform," Journal of Public Economics, 6, pp. 77-104.

[13] Fleurbaey, Marc and Francois Maniquet (2006). "Fair Income Tax," Review of Economic Studies, 73.

[14] Foley, Duncan (1970). "Lindahl's Solution and the Core of an Economy with Public Goods," Econometrica, 38.

[15] Gaertner, Wulf and Erik Schokkaert (2012). Empirical Social Choice: Questionnaire-Experimental Studies on Distributive Justice. Cambridge.

[16] Gelber, Alexander and Matthew Weinzierl (2015), "Equalizing Outcomes and Equalizing Opportunities: Optimal Taxation when Children's Abilities Depend on Parents' Resources," National Tax Journal.

[17] Hasen, David M. (2007). "Liberalism and Ability Taxation," Texas Law Review 85(5), April.

[18] Hellwig, Martin (2005), "A utilitarian approach to the provision and pricing of excludable public goods," Journal of Public Economics, 89(11-12), pp. 1981-2003.

[19] Hines, James R. (2000). "What is benefit taxation," Journal of Public Economics, 75.

[20] Institute of Fiscal Studies, Mirrlees, J.A., S. Adam, T. Besley, R. Blundell, S. Bon, R. Chote, M. Gammie, P. Johnson, G. Myles, and J. Poterba (eds.) (2010) Dimensions of Tax Design: The Mirrlees Review. Oxford University Press.

[21] Kaneko, Mamoru. (1977a) "The Ratio Equilibria and a Voting Game in a Public Goods Economy, " Journal of Public Economics, 16, pp. 123-136 
[22] Kaneko, Mamoru. (1977b) "The Ratio Equilibria and the Core of the Voting Game G(N, W) in a Public Goods Economy, " Econometrica, 45(7), pp. 1589-1594

[23] Kapicka, Marek. 2006. "Optimal Income Taxation with Human Capital Accumulation and Limited Recordkeeping." Review of Economic Dynamics 9(4): 612-639.

[24] Kaplow, Louis (2008). The Theory of Taxation and Public Economics, Princeton.

[25] Kaplow, Louis and Steven Shavell (2001). "Any non-welfarist Method of Policy Assessment Violates the Pareto Principle," Journal of Political Economy 109(2).

[26] King, Mervyn A. (1983). "An Index of Inequality: With Applications to Horizontal Equity and Social Mobility," Econometrica.

[27] Lindahl, Erik (1919). "Just Taxation - A Positive Solution" (E. Henderson, transl.) in Musgrave, Richard A. and A.T. Peacock, Eds, Classics in the Theory of Public Finance. Macmillan.

[28] Lockwood and Weinzierl (2015a). "De Gustibus non est Taxandum," Journal of Public Economics, 124.

[29] Lockwood and Weinzierl (2015b). "Positive and Normative Judgments Implicit in U.S. Tax Policy, and the Costs of Unequal Growth and Recessions." Journal of Monetary Economics (forthcoming).

[30] Mankiw and Weinzierl (2009). "The Optimal Taxation of Height," American Economic Journal: Economic Policy, 2.

[31] Markovits, Daniel (2003), "How Much Redistribution Should There Be?" Yale Faculty Scholarship Series. Paper 412

[32] Matsumoto, Mutsumi, (2001), "Public Input Provision in an Optimal Income Tax Model," FinanzArchiv.

[33] Mill, John Stuart (1871). Principles of Political Economy. Oxford University Press, 1994. Book V, page 169.

[34] Mirrlees, J.A., (1971). "An Exploration in the Theory of Optimal Income Taxation," Review of Economic Studies 38, 175-208.

[35] Moulin, Herve (1987). "Egalitarian-Equivalent Cost Sharing of a Public Good," Econometrica, 55.

[36] Murphy, Liam and Thomas Nagel (2002), The Myth of Ownership, Oxford: Oxford University Press.

[37] Musgrave, Richard A. (1959). The Theory of Public Finance. McGraw-Hill.

[38] Nozick, Robert (1974). Anarchy, State, and Utopia. New York: Basic Books.

[39] Petty, William (1677). "A Treatise of Taxes and Contributions," cited in Musgrave (1959).

[40] Rakowski, Eric (2000). "Can Wealth Taxes be Justified," NYU Tax Law Review, 53.

[41] Rawls, John (1971). A Theory of Justice. Cambridge: Harvard University Press.

[42] Rawls, John (2001). Justice as Fairness. Cambridge: Harvard University Press.

[43] Roemer (1998). Equality of Opportunity, Harvard. 
[44] Saez, Emmanuel and Stefanie Stantcheva (2015). "Generalized Social Welfare Weights for Optimal Tax Theory." American Economic Review.

[45] Salanié, Bernard, (2011). The Economics of Taxation. Cambridge: MIT Press..

[46] Samuelson, Paul A, (1954). "The Pure Theory of Public Expenditure," Review of Economics and Statistics.

[47] Samuelson, Paul A, (1955). "Diagrammatic Exposition of a Theory of Public Expenditure," Review of Economics and Statistics, 37(4), November.

[48] Seligman, Edwin R. A. (1908), "Progressive Taxation in Theory and Practice," American Economic Association Quarterly.

[49] Shaviro, Daniel (2002), "Endowment and Inequality," in Thorndike and Ventry Jr., eds., Tax Justice: The Ongoing Debate. Urban Institute.

[50] Shaviro, Daniel (2013). "The Forgotten Henry Simons," NYU Law School Working Paper.

[51] Sheffrin, Steven M. (2013). Tax fairness and Folk Justice. New York: Cambridge University Press.

[52] Simons, Henry (1938). Personal Income Taxation. Chicago: University of Chicago.

[53] Smith, Adam (1776). An Inquiry into the Nature and Causes of the Wealth of Nations.

[54] Stantcheva, Stefanie, (2014), "Optimal Taxation and Human Capital Policies over the Life Cycle," Working paper.

[55] Stark, Kirk J. (2005). "Enslaving the Beachcomber: Some Thoughts on the Liberty Objections to Endowment Taxation," UCLA Law and Economics Research Series.

[56] Stiglitz, Joseph (1987). "Pareto Efficient and Optimal Taxation and the New New Welfare Economics," Handbook of Public Economics, Chapter 15.

[57] Sugin, Linda (2011). "A Philosophical Objection to the Optimal Tax Model," NYU Tax Law Review.

[58] Weinzierl, Matthew (2014). "The Promise of Positive Optimal Taxation: Normative Diversity and a role for Equal Sacrifice," Journal of Public Economics, 118.

[59] Weinzierl, Matthew (2015). "Popular Acceptance of Morally Arbitrary Luck and Widespread Support for Classical Benefit-Based Taxation," working paper.

[60] Werning, Ivan, (2007). "Pareto Efficient Income Taxation," Working Paper, MIT, April.

[61] West, E.G. and R.J. Staaf (1979), "The Distributional Implications of Public Goods Revisited," Econometrica, 47.

[62] Zelenak, Lawrence (2006). "Taxing Endowment," Duke Law Journal, 55(6), April. 